\title{
Patterns of Inter- and Intralaminar GABAergic Connections Distinguish Striate (V1) and Extrastriate (V2, V4) Visual Cortices and Their Functionally Specialized Subdivisions in the Rhesus Monkey
}

\author{
M. F. Kritzer, ${ }^{1, a}$ A. Cowey, ${ }^{2}$ and P. Somogyi ${ }^{1}$ \\ 'MRC Anatomical Neuropharmacology Unit, Oxford, OX1 3TH United Kingdom and ${ }^{2}$ Department of Experimental \\ Psychology, University of Oxford, Oxford, OX1 3UD United Kingdom
}

Local GABAergic connections are undoubtedly important for the operation of cerebral cortex, including the tuning of receptive field properties of visual cortical neurons. In order to begin to correlate specific configurations of GABAergic networks with particular receptive field properties, we examined the arrangement of GABAergic neurons projecting to foci in compartments of known functional specialization in striate (area V1) and extrastriate (areas V2, V4) cortices of rhesus monkeys.

GABAergic cells were detected autoradiographically following microinjections into supragranular, granular, or infragranular layers of 5,10 , or $50 \mathrm{nl}$ of ${ }^{3} \mathrm{H}$-nipecotic acid, which selectively exploits the GABA reuptake mechanism. These injections produced complex inter- and intralaminar distributions of retrograde perikaryal labeling that was selective for GABA-immunopositive neurons and glia. The pattern of retrograde labeling depended on both the laminar and cytoarchitectonic location of injection sites. In all cases, a high density of labeled neurons was present in the immediate vicinity of injection sites, with the density of labeled neurons decreasing for the most part uniformly with horizontal distance. Injections in supragranular layers produced relatively widespread tabeling (up to 1.5-1.7 $\mathrm{mm}$ from the center of injections) in upper layers, whereas in granular and infragranular layers, labeling was confined to a radius of $0.25-$ $0.5 \mathrm{~mm}$. Conversely, injections in infragranular layers produced labeling that was widest (up to $1 \mathrm{~mm}$ ) in lower layers, but more laterally restricted in supragranular layers. Injections in granular layers, on the other hand, produced an even distribution of labeling, $0.6-1.0 \mathrm{~mm}$ in diameter, throughout all layers. Comparably placed injections in V1, V2, and V4 resulted in patterns of labeling that were distinguished by features including stepwise increases in the lateral extent of labeling from striate to extrastriate areas, and the circular versus markedly elongated intralaminar distribution of labeled neurons in V1 and V4 versus V2. Further, for super-

\footnotetext{
Received Jan. 23, 1992; revised June 8, 1992; accepted June 24, 1992.

We thank Mrs. S. Mygdal, Mr. M. J. E. Brown, Miss Diane Lataweic, and Mr J. D. B. Roberts for excellent technical assistance. We also thank Dr. Z. F. Kisvarday for his contributions to pilot experiments that led to this project, Dr. J. A. Matsubara for encouraging the use of ${ }^{3} \mathrm{H}$-nipecotic acid, Dr. S. Zeki and Mr. Ian Wilson for advice in tissue preparation, Mr. Frank Kennedy for photographic assistance, and Dr. T. Cunnane for assistance with computerized three-dimensional reconstructions. M.F.K. was supported by a National Institutes of Health postdoctoral fellowship (NS08675).

Correspondence may be addressed to any of the authors.

aresent address: Section of Neurobiology, Yale University School of Medicine 333 Cedar Street, New Haven, CT 06510.

Copyright (C) 1992 Society for Neuroscience $0270-6474 / 92 / 124545-20 \$ 05.00 / 0$
}

ficial injections, labeling was present in all layers in V1 and V2, but did not extend below the top of layer $V$ in area $\mathbf{V 4}$. These findings offer clear examples of organizational differences in the intrinsic inhibitory connections of visual cortices. The results also demonstrate that the number of GABAergic neurons projecting to any spot in cortex decreases systematically with horizontal distance from the spot, and that radiolabeled cells do not coalesce to form slabs, columns, or clusters. This relatively even distribution of retrogradely labeled cells in the tangential plane is consistent with recent computer simulations (Worgotter and Koch, 1991) that suggest that inhibitory neurons broadly tuned as a population can produce the specific response properties of cortical neurons.

Injections fortuitously confined to cytochrome oxidase compartments, for example, blobs or stripes in V1 and V2, produced most labeling within like compartments. However, some labeling always traversed these histochemical boundaries. Thus, inhibitory connections within $V_{1}$ and $V_{2}$ may provide a means for cross talk between discrete channels of visual information, whose anatomical segregation has been a hallmark of $V_{1}$ and $\mathbf{V} 2$ organization.

Within the cerebral cortex, there are two broad families of neurons: the spiny cells, including pyramidal cells and spiny stellates, which use excitatory amino acids as transmitter, and smooth or sparsely spiny cells, which use inhibitory amino acids as transmitter. Both families consist of many different types of neuron exhibiting distinctive laminar distributions, morphology, biochemical characteristics, and synaptic connections (e.g., Somogyi, 1989). Across the cytoarchitectonic divisions of the cortex, however, many of the same types of neuron can be recognized, suggesting that at a cellular level similar operations are carried out from area to area, independent of the modality of activating inputs. Nonetheless, within cortical regions devoted to a single modality such as vision, neurons in different layers or in different visual cortical areas can have markedly different response properties. The question thus arises as to whether and, if so, how the basic connectional blueprint of the cortex has been modified during evolution to support particular functional demands. These types of questions are perhaps best explored in the visual cortex of primates, where both histologically and functionally recognizable areas have been delineated and the properties of cells well characterized. Recently, the intracortical connections made by the excitatory family of cells have been compared from layer to layer in the primary visual area V1 of macaque monkeys (Kisvarday et al., 1989), revealing 
major differences in inter- and intralaminar organization also found in previous studies without identification of the nature of transmitters (e.g., Ramon y Cajal, 1911; Lund and Boothe, 1975). However, about every fifth cortical neuron contains the inhibitory transmitter GABA, and in the present study we asked whether the patterns of connections of this second family of cortical cells also differ from layer to layer, and from one visual cortical area to another.

Golgi impregnation and injection of HRP into single cells have provided detailed knowledge of the morphology and axonal trajectories of individual presumed or identified inhibitory cells (e.g., Ramon y Cajal, 1891; Szentagothai, 1969; Valverde, 1971; Peters and Regidor, 1981; Martin et al., 1983; Somogyi et al., 1983b; Lund, 1987; Lund et al., 1988; Lund and Yoshioka, 1991), and immunocytochemical studics in primates demonstrate that the heterogeneous populations of GABA- and/or glutamic acid decarboxylase-immunopositive neurons and their terminals show selectivity in their distribution across cortical areas and layers (e.g., Hendry et al., 1987; Schwartz et al., 1988; Fitzpatrick et al., 1987). However, insight into the organization of GABAergic neurons into inhibitory circuits is more limited, stemming mainly from studies that exploit the relatively selective uptake and retrograde transport of ${ }^{3} \mathrm{H}-\mathrm{GABA}$ by GABAergic terminals (see Streit et al., 1979; Cuenod et al., 1982; but see Zucker et al., 1984). In the primary visual cortex, studies in which microinjections of ${ }^{3} \mathrm{H}-\mathrm{GABA}$ were made in specific cortical layers have begun to lay the foundations for identifying layer-specific inhibitory connections in rats (Chronwall and Wolff, 1980; Somogyi et al., 1981b; Wolff and Chronwall, 1982), cats (Hamos et al., 1983; Kisvarday et al., 1987), and monkeys (Somogyi ct al., 1981a, 1983a; DeFelipe and Jones, 1985). Nonetheless, relationships between configurations of GABAergic circuits and specific types of visual information processing were not established. In the present study, advantage was taken of the unique mapping of function onto identifiable regions in visual areas of the primate cortex, as the organization of GABAergic circuitry was explored in relation to cortical landmarks of lamination and/or patterns of activity of the mitochondrial enzyme cytochrome oxidase (CO), which delineate subdivision of the primary (V1) and associational (V2) visual cortices devoted to information processing relevant to the perception of color, form, or motion (see DeYoe and Van Essen, 1988; Livingstone and Hubel, 1988; Martin, 1988a; Zeki and Shipp, 1989). Analyses were also made in an additional visual association area, area $\mathrm{V} 4$, which represents a region more specialized for the visual attributes of color and form (Zeki, 1978; Schein and Desimonc, 1990). One of our primary interests was whether structural differences in inhibitory cortical networks parallel functional subdivision. We therefore analyzed and compared the distribution of GABAergic neurons, retrogradely labeled following selective microinjections of ${ }^{3} \mathrm{H}$-nipecotic acid, a highly potent and selective competitor with GABA for high-affinity GABA uptake (e.g., Krogsgaard-Larsen and Johnston, 1975), in specific layers and $\mathrm{CO}$ compartments of the striate and extrastriate cortices of the rhesus monkey where neurons with particular receptive field properties are concentrated.

\section{Materials and Methods}

\section{Animals and surgical procedures}

Tissue from five macaque monkeys ( Macaca mulatta) was used. All the animals were mature female exbreeders that were unsuitable for longterm experiments. Prior to surgery, animals were sedated with ketamine
(Ketalar, Parke-Davis; $10 \mathrm{mg} / \mathrm{kg}$, i.m.), and deep anesthesia was initiated and maintained by intravenous sodium pentabarbitone (Intraval, May and Baker). Decadron $(10 \mathrm{mg} / \mathrm{kg}$ ) was also administered intravenously at the start of the procedure to minimize edema. After placing animals in a stereotaxic apparatus, bilateral craniotomies exposing the anterior two-thirds of the occipital lobe and the posterior parietal lobe were made; the dura was left intact until immediately prior to injection in a given hemisphere. Procedures were carried out with the aid of a stereo operating microscope.

\section{Injections and isotope}

Injections were delivered by pressure through fine glass capillaries (tip diameter, $30-50 \mu \mathrm{m}$ ). They were placed by visual inspection and were made as close to perpendicular to the pial surface as possible. ${ }^{3} \mathrm{H}$ nipecotic acid (Amersham; $25.8 \mathrm{Ci} / \mathrm{mmol}$ ) was injected in artificial ccrebrospinal fluid containing $5 \mu \mathrm{l} / \mathrm{ml}$ of colloidal gold (10 $\mathrm{nm}$ diameter) conjugated to wheat germ agglutinin (Sigma) used as a marker for injection sites. This cyclic amino acid compound is one of the most potent inhibitors of the high-affinity GABA transport system and has been shown to compete with GABA for uptake into brain slices (Johnston et al., 1976), synaptosomal preparations (Kovalev and Raevskii, 1981), and glial cultures (Larsson et al., 1980) with an apparent affinity equal to or greater than that of GABA itself. The final concentration of isotope and ligand was $1 \mu \mathrm{Ci} / 100 \mathrm{nl}$ and $0.38 \mathrm{~mm}$, respectively. Injection volumes were carefully controlled by visual monitoring of the meniscus within the calibrated capillaries with an eyepiece graticule in the operating microscope and were either 5, 10, or $50 \mathrm{nl}$. Each of these volumes was injected over 5-10 min, and the capillary was kept in place for at lcast $5 \mathrm{~min}$ following cach injection. In cach hcmisphcre, injections (at least $5 \mathrm{~mm}$ apart) were placed at varying depths within representations of the central $10^{\circ}$ of the visual field in V1. The portion of V2 located on the posterior bank of the lunate sulcus was also injected; this region was approached by traversing rostral area V1 $(2 \mathrm{~mm}$ posterior to the lunate sulcus) and the underlying white matter to reach cortex beneath the operculum. In one case, the region of area V2 located on the lateral surface of the occipital lobe, immediately posterior to the lunate sulcus, was injected. The portion of area V4 located on the gyral surface between the lunate and lateral sulci, and dorsal to the inferior orbital sulcus, corresponding to area V4D (see Felleman and Van Essen, 1991), was also injected. In three animals, V1, V2, and V4 were injected, and in two cases only V1 and V2 were targeted. Across cases, the order in which these three areas were injected was systematically varied so that injections in $\mathrm{V} 1, \mathrm{~V} 2$, and $\mathrm{V} 4$ with minimal (40 $\mathrm{min}$ ) and maximum (8 hr) survival times were obtained; no quantitative or qualitative differences in retrograde labeling were observed for any groups of injections within this range of survival times. Between 10 and 30 injections were made in each animal, and a total of 41 injection sites were selected for evaluation in this study; the number of injection sites targeting specific layers for each area is presented in the Results, and is also presented in Table 1 .

\section{Perfusion and tissue processing}

Forty minutes after the last injection, animals were perfused transcardially with up to 1 liter of Tyrode's solution, followed by 2-3 liters of fixative [ $1 \%$ paraformaldehyde (TAAB), $2 \%$ glutaraldehyde (TAAB) in $0.1 \mathrm{M}$ phosphate buffer (PB)]. Immediately following the perfusion, the occipital operculi were dissected from each hemisphere according to the methods of Shipp and Zeki (1989b). First, cuts were made along the fundi of the lunate, inferior occipital, and calcarine sulci. Operculi were then removed following a second series of cuts severing the intervening stretches of cortex linking these sulci. Blocks containing area V4 were also dissected. Following postfixation (up to $2 \mathrm{hr}$ ), blocks were transferred to PB containing $10 \%, 20 \%$, and finally $30 \%$ sucrose, over the course of $3 \mathrm{~d}$; during this period, blocks were kept at $4^{\circ} \mathrm{C}$ and subjected to gentle agitation. Once sunk in sucrose, blocks were prepared for sectioning on a freezing microtome. For tissue to be sectioned parallel to the pia, opercular and posterior parietal blocks were flattened gently between two glass slides before being mounted on the microtome chuck; the upper slide was kept in place while the tissue was rapidly frozen, and was used as a guide in adjusting the knife to produce sections as close to horizontal as possible. The slide was removed by gentle warming prior to sectioning. All sections were cut at a thickness of $30 \mu \mathrm{m}$, and collected sequentially in cold PB. After rinsing in PB, alternate sections were processed for either cytochrome oxidase staining or silver intensification of colloidal gold and autoradiography. 
Cytochrome oxidase. The cytochrome oxidase procedures were adapted for free-floating sections from the procedures of Silverman and Tootell (1987). Following initial rinsing in $0.1 \mathrm{M} \mathrm{PB}$, sections were pretreated in $1 \%$ sodium borohydride in $0.1 \mathrm{M} P B$ for $30 \mathrm{~min}$. Following extensive rinsing in $\mathrm{PB}$, they were rinsed in $4 \times 10 \mathrm{~min}$ changes of $0.1 \mathrm{MPB}$ containing $10 \%$ sucrose, and then incubated for $10 \mathrm{~min}$ in $0.05 \mathrm{M}$ Tris ( $\mathrm{pH} 7.6$ ) containing cobalt chloride ( $275 \mathrm{mg} / \mathrm{liter}), 10 \%$ sucrose, and $0.5 \%$ dimethyl sulfoxide (DMSO). After a final brief rinse in PB (with $10 \%$ sucrose), sections were incubated at $40^{\circ} \mathrm{C}$ in an oxygenated solution

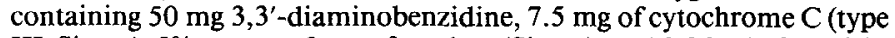
III, Sigma), $5 \%$ sucrose, $2 \mathrm{mg}$ of catalase (Sigma), and $0.25 \mathrm{ml}$ of DMSO/ $100 \mathrm{ml}$ of $0.1 \mathrm{M} \mathrm{PB}$. Staining of satisfactory contrast was generally achieved in less than $4 \mathrm{hr}$.

Silver intensification. Silver intensification of colloidal gold was carried out on free-floating sections by washing sections in $3 \times 20 \mathrm{~min}$ changes of citrate-acetate buffer (pH 5.5) prior to developing for $40 \mathrm{~min}$ in a solution composed of equal volumes of Initiator and Enhancer solutions (Janssen Kit, IntenSE BL). Sections were then rinsed briefly in citrate-acetate buffer, fixed for $10 \mathrm{~min}$ in $2.5 \%$ sodium thiosulfate in $\mathrm{dH}_{2} \mathrm{O}$, and rinsed thoroughly in $0.1 \mathrm{M} P \mathrm{~PB}$. They were then mounted on ordered, gel-subbed slides.

Autoradiography. Autoradiography was carried out on slide-mounted material that had been processed for silver intensification (see above). The methods used are identical to those described by Somogyi et al. (1981 a, 1983a). Slides were dipped in Ilford K5 nuclear emulsion, stored at $4^{\circ} \mathrm{C}$ for $10-15 \mathrm{~d}$, and then developed using Kodak D-19B developer diluted 1:1 with distilled water, and counterstained with cresyl violet.

\section{Control experiments}

Adjacent semithin sections $(0.5 \mu \mathrm{m})$ cut from resin-embedded (Durcupan, Fluka) tissue sections containing injection sites were mounted on scrially ordered, gelatin-subbed slides. Altcrnate slides were dipped for autoradiography (as above, exposed for 4-8 weeks), or immunoreacted with anti-GABA (diluted 1:2000) antiserum according to procedures of Somogyi et al. (1985) and visualized with a peroxidaseconjugated secondary antibody and 3,3'-diaminobenzidine.

\section{Anatyses}

Radiolabeled cells were identified as those where silver grain density was at least four times higher than that of the nearest three somata (Fig. $1 C-E$ ). Neuronal somata were distinguished from labeled glia according to the standard cytological features revealed in cresyl violet staining and by cell size (Fig. $1 C-E$ ). The specificity of high-affinity uptake of ${ }^{3} \mathrm{H}$-nipecotic acid for GABAergic neurons was established by aligning camera lucida images drawn at $25 \times$ obtained from semithin sections processed for autoradiography and adjacent sections stained with antiGABA antiserum (Fig. 1 $A, B$ ).

The laminar location of injection sites was determined by the accumulations of silver grains in autoradiograms. In adjacent sections reacted for cytochrome oxidase, evidence of slight tissue distortion was also used to assess the position of the capillary tip. In most cases, the capillary tip was also identified independently prior to autoradiography by the localization of silver-enhanced gold particles injected along with the isotope.

The three-dimensional distribution of cells retrogradely labeled following individual injections was obtained by compiling camera lucida drawings (drawn with a $25 \times$ objcctivc) that marked the positions of labeled neurons and blood vessels obtained from all sections processed for autoradiography, which included a given injection site. The laminar location of cells was assigned on the basis of cytoarchitecture revealed in cresyl violet staining. For horizontal sections through area V1, the characteristic patterns of cytochrome oxidase staining in alternate sections were also used in establishing the identity of cortical layers. The lateral extent of labeling was assessed relative to the axis of the injection site, defined by a vertical line passing through the injection site and running perpendicular to cortical lamination. Three-dimensional reconstruction was carried out using a digitizing tablet and MACSTEREOLOGY software (Runturly Microsystems, UK).

\section{Results}

General features of ${ }^{3} \mathrm{H}$-nipecotic acid labeling

The relationship between the halo of silver grains marking the position of the capillary tip (see Fig. $6 B$ ) and the zone of effective tracer uptake is uncertain. However, injections placed in similar
Table 1. Lateral distance in millimeters from the central axis of the injection of retrograde labeling of neurons within cortical layers of striate and extrastriate areas following placement of ${ }^{3} \mathrm{H}$-nipecotic acid injections (10 nl) in supragranular (layers I-III), granular (layer IV), and infragranular (layers V-VI) cortical layers

\begin{tabular}{|c|c|c|c|c|c|}
\hline Area & $\begin{array}{l}\text { Layer } \\
\text { II }\end{array}$ & $\begin{array}{l}\text { Layer } \\
\text { III }\end{array}$ & $\begin{array}{l}\text { Layer } \\
\text { IV }\end{array}$ & $\begin{array}{l}\text { Layer } \\
\text { V }\end{array}$ & $\begin{array}{l}\text { Layer } \\
\text { VI }\end{array}$ \\
\hline \multicolumn{6}{|c|}{ Injections in supragranular layers } \\
\hline $\mathrm{V} 1(n=11)$ & $1.0-1.5$ & $0.5-0.7$ & 0.2 & $0.3-0.6$ & $0.25-0.3$ \\
\hline $\mathrm{V} 2(n$ & 0.7 & & & 0.7 & $0.5-0.6$ \\
\hline $\mathrm{V} 4(n$ & $1.3-$ & & & $.8^{b}$ & No \\
\hline \multicolumn{6}{|c|}{ Injections in granular layers ${ }^{c}$} \\
\hline $\mathrm{V} 1(n=9)$ & $0.2-0.4$ & 0.2 & & 4 & $0.2-0.4$ \\
\hline $\mathrm{V} 2($ & 0.6 & 0 & 8 & .8 & $0.6-0.8$ \\
\hline $\mathrm{V} 4(n=2)$ & $0.8-1.0$ & $0.8-1$. & & $0.6-0.8^{b}$ & No label \\
\hline \multicolumn{6}{|c|}{ Injections in infragranular layers } \\
\hline $\mathrm{V} 1(n=2)$ & $0.3-0.5$ & $0.3-0.5$ & & & $0.7-0.9$ \\
\hline $\mathrm{V} 2(n=2)$ & $0.5-0.7$ & $0.6-0.7$ & $0.5-0.7$ & $1.0-1.1$ & $1.0-1.1$ \\
\hline $\mathrm{V} 4(n=2)$ & $0.5-0.8$ & $0.7-0.8$ & $0.6-0.7$ & $0.7-0.8$ & $0.4-0.6$ \\
\hline
\end{tabular}

The range of values given for a particular layer encompasses all values for lateral distance obtained from sites evaluated for that group. Patterns of heavily labeled cells representing particularly strong projections and specific to certain layers are described in the Results.

- Values represent range across all subdivisions of layer IV.

$b$ Values for upper layer $\mathrm{V}$ only.

Values represent distance across long, that is, anteroposterior axis.

laminar locations but varying in volume from 5 to $50 \mathrm{nl}$ produced similar patterns of labeling. In addition, movement of the capillary tip vertically by just $100-200 \mu \mathrm{m}$ in many cases produced markedly different patterns of retrograde labeling (e.g., see Fig. $3 C, D$ ). We therefore assume that efficient uptake of ${ }^{3} \mathrm{H}$ nipecotic acid and the slow delivery of tracer combined to produce highly circumscribed zones of effective tracer uptake.

The vast majority of silver grains associated with individual cortical injections were concentrated over neuronal and glial cell bodies (Figs. 1, 2). Radiolabeled neurons were found up to several millimeters in all dircctions from injection sites (e.g., Fig. 3). The neurons did not follow a Gaussian distribution, but exhibited clear anisotropies in both the vertical, that is, perpendicular to the pial surface, and horizontal, that is, parallel to the pial surface, directions (e.g., Figs. 3-5), consistent with axonal uptake and retrograde transport of the tracer. Variability in silver grain density over individual neurons falling within the range considered as labeled (see Materials and Methods; e.g., Figs. $1 C-E ; 6 C, D)$ was also found and was independent of both the distance from the injection site and the time interval between injection and fixation. The degree of labeling was taken as an index of the proportion of terminals that the radiolabeled neurons maintained in proximity to injection sites.

Moderate grain density was also observed over the neuropil (Figs. 1, 2). This labeling, including the injection sites, represented ${ }^{3} \mathrm{H}$-nipecotic acid arrested within cell processes, for example, axons and terminals, at the time of fixation. For all injections, neuropil labeling was most dense along the radial axis of the injection. However, radioactivity within the neuropil was insufficient to provide a clear image of fascicular organization in either coronally or horizontally sectioned material.

\section{Selectivity of ${ }^{3} \mathrm{H}$-nipecotic acid for GABAergic neurons}

Retrograde labeling was selective to the extent that only some neurons within any given field were labeled (e.g., Figs. 1, 2). 


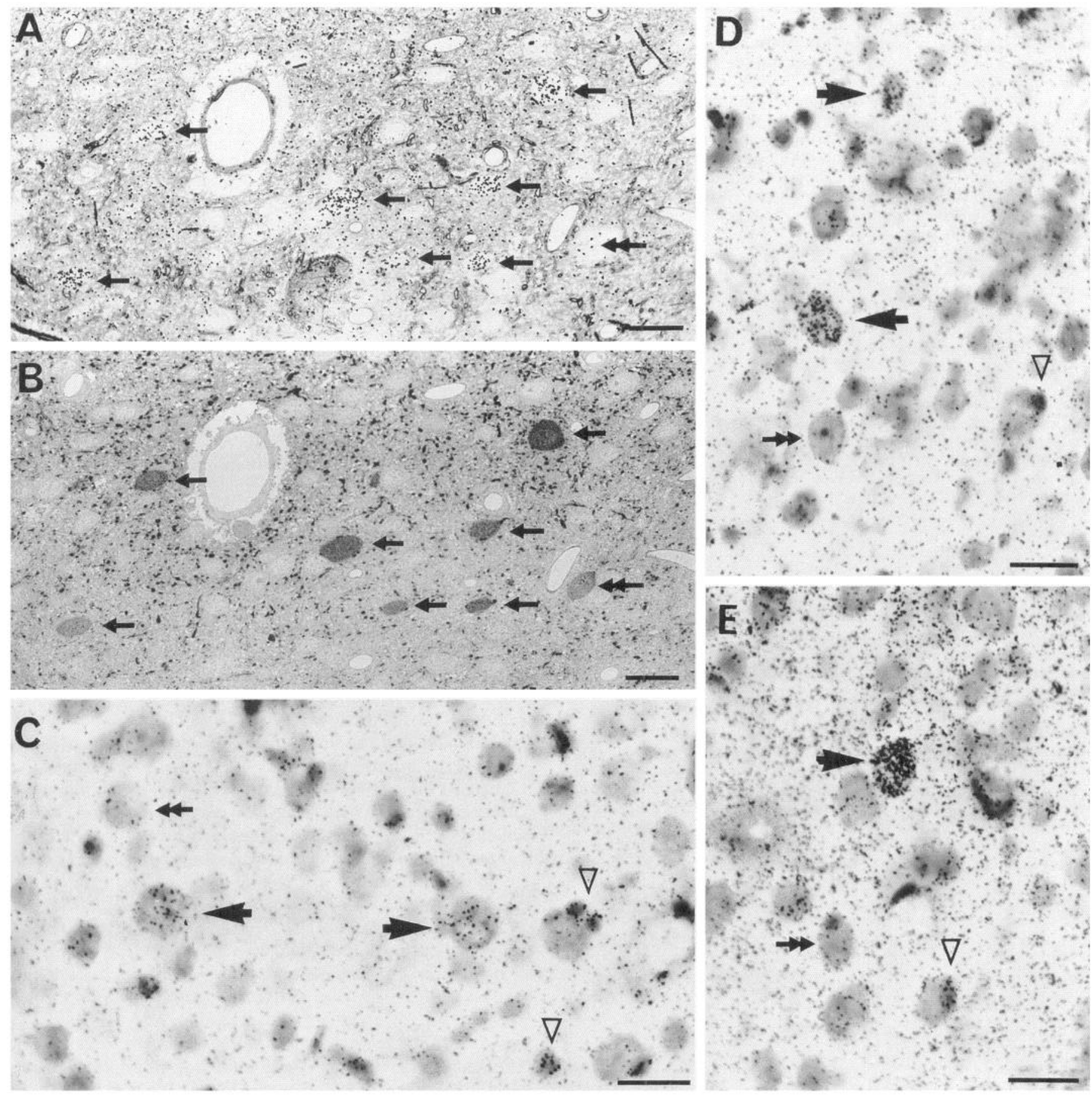

Figure 1. Selectivity of ${ }^{3} \mathrm{H}$-nipecotic acid uptake: semithin $(A$ and $B, 0.5 \mu \mathrm{m})$ and frozen sections $(C-E, 30 \mu \mathrm{m})$ showing GABAergic neurons and glia selectively labeled following injection of ${ }^{3} \mathrm{H}$-nipecotic acid $(10 \mathrm{nl}, 0.38 \mathrm{~mm}) . A$ and $B$, All radiolabeled neurons in a coronal section through layers II and III of area V1 ( $A$, single arrows) correspond to cells in an adjacent section ( $B$, single arrows) that are immunoreactive for GABA; one GABA-positive neuron $(B$, double arrow) is not labeled autoradiographically $(A$, double arrow). $C-E$, Silver grains in frozen sections counterstained with cresyl violet are found over cells and neuropil. Two neurons (large single arrows) whose grain density is roughly that of the surrounding neuropil, but at least four times higher than nearby neurons (double arrows, $C-E$ ), are considered labeled by our criteria. Retrogradely labeled neurons are distinguished from radiolabeled glia (e.g., open arrowheads, $C-E$ ) by their larger size and cytological characteristics. Scale bars, $20 \mu \mathrm{m}$.

Even within the dense halo of silver grains surrounding injection sites, many more unlabeled than labeled neurons were present. We compared semithin sections in area V1 prepared for autoradiography (Fig. 1A) with adjacent sections processed for GABA immunoreactivity (Fig. $1 B$ ). GABA immunoreactivity corresponded to the expected pattern of strongly immunoreactive neurons scattered in all cortical layers, and an abundance of strongly reactive terminals, often outlining immunonegative cell bodies (Fig. 1B). Analyses based on examination of a total of four injection sites $(10 \mathrm{nl}$ volume, $0.1 \mathrm{mCi}$ isotope, $0.38 \mathrm{~mm}$ nipecotic acid; three superficially placed, one in layer IV) from two animals showed that each of the 98 radiolabeled cells iden- 

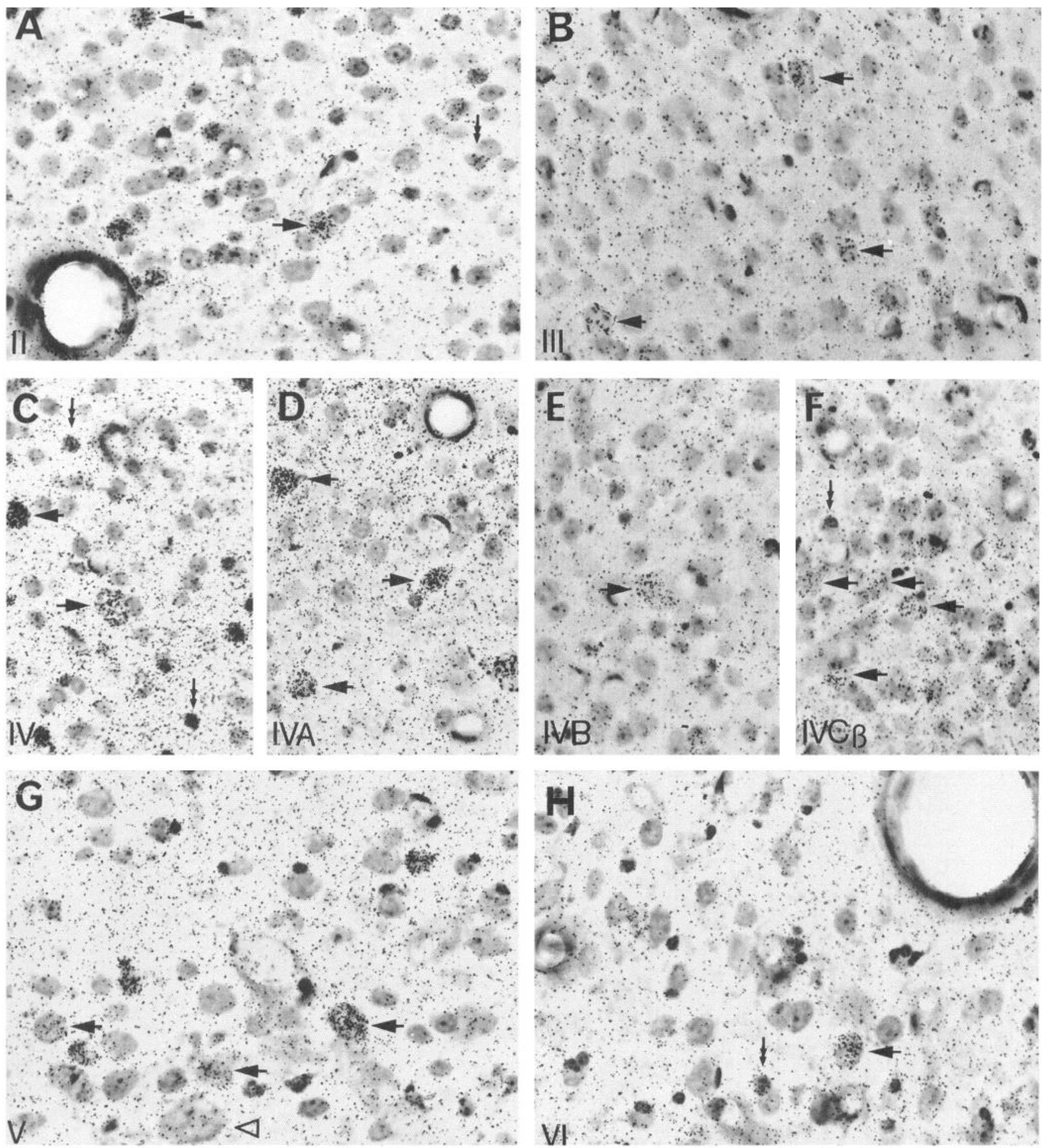

Figure 2. Neurons retrogradely labeled by ${ }^{3} \mathrm{H}$-nipecotic acid-labeled $(10 \mathrm{nl}, 0.38 \mathrm{~mm})$ in different cortical layers (single arrows, $\left.A-H\right)$ : frozen sections cut parallel to the pial surface and counterstained with cresyl violet. In layer II, retrogradely labeled neurons $(A$, area V2) are mainly small, whereas labeling in layer III ( $B$, area V1) involves both small- and medium-sized cells. Layer IVC of V1 $(F)$ is unique for its high density of small radiolabeled neurons; retrograde labeling in other subdivisions of layer IV of area V1 $(D, E)$ and layer IV of extrastriate areas $(C$, V4) is associated with the largest neurons. In layers V $(G$, area V4) and VI $(H$, area V1), small- and medium-sized, radiolabeled neurons are interspersed among large, unlabeled neurons (e.g., open arrowhead, $G$ ). Glial cells (double arrows, $A, C, F$, and $H$ ) are also radiolabeled. Scale bars, $20 \mu \mathrm{m}$.

tified in layers II, III, IVA,B, V, and VI corresponded to either glia or GABA-positive neurons. In layer IVC, 20 of 21 radiolabeled cells were positively identified as either glia or GABAimmunoreactive neurons; it was uncertain whether one radio- labeled soma was a glial cell or small, GABA-negative neuron. Thus, with the exception of glial cells, neurons labeled with ${ }^{3} \mathrm{H}$ nipecotic acid were strongly GABA immunoreactive (Fig. $1 A, B$, single arrows). In all layers, however, a substantial proportion 
A

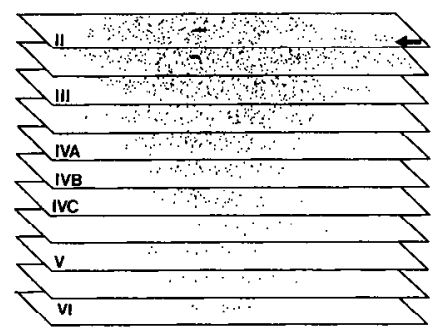

B

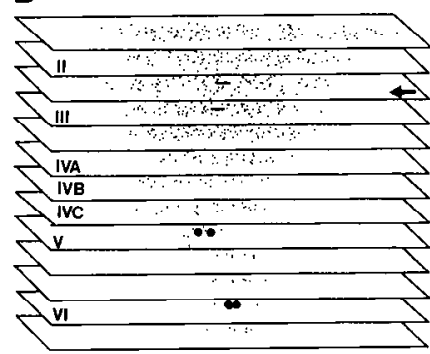

C

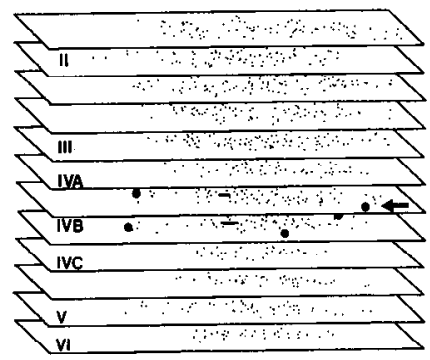

A
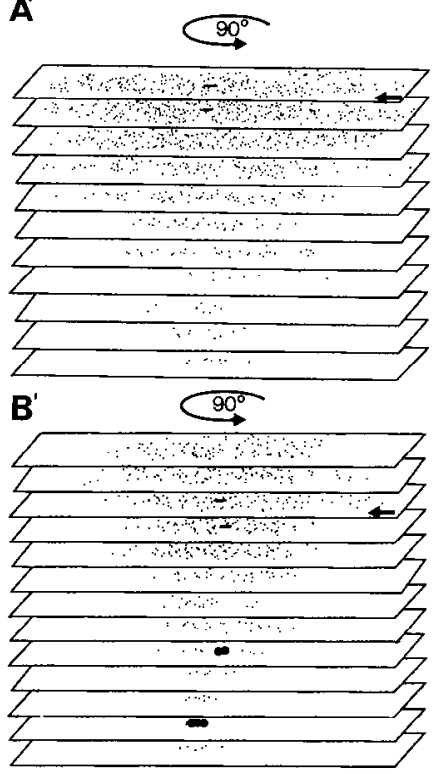

D

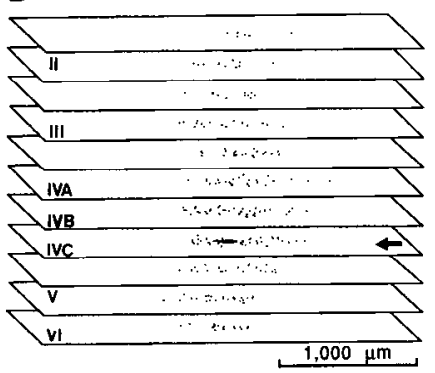

Figure 3. Three-dimensional pattern of retrograde labeling in area Vl reconstructed from horizontal sections: injection of ${ }^{3} \mathrm{H}$-nipecotic acid $(10 \mathrm{nl}, 0.38 \mathrm{~mm})$ into supragranular $(A, B)$ and granular $(C, D)$ layers. Small dots correspond to radiolabeled neurons; the rare large dots, to particularly strongly labeled cells; and small shaded areas (at the level of arrows), to the small, dense halos of silver grains identifying injection sites. The distance between sections is expanded for clarity; these conventions are used in all reconstructions presented (Figs. 6-8, 10). The similarity in dimensions of reconstructions rotated through $90^{\circ}$ $\left(A, A^{\prime} ; B, B^{\prime}\right)$ illustrates the circular symmetry of labeling within individual layers. Injection of superficial layers labels neurons up to $1.0-1.2$ $\mathrm{mm}$ lateral to the axis of the injection in layers II/III but produces more circumspect labeling in granular and infragranular layers. $B$, Small numbers of neurons in upper layers V and VI (large dots) are strongly labeled specifically in conjunction with injections spanning lower layer II to middle layer III (see also Fig. 4). $C$, Injection of layer IVB produces widespread labeling in all layers, particularly layers II, III, and V. A striking group of neurons within layer IVB (large dots) lying up to $0.7-$ $0.9 \mathrm{~mm}$ from the injection site are very strongly labeled (see also Fig. 5 ). $D$, Injection in layer IVC produces a laterally restricted, cylindrical array of retrograde labeling spanning all cortical layers, with particularly weak and sparse labeling in supragranular layers.

of GABA-immunopositive neurons lying within the circumference of retrograde labeling failed to show above-background densities of silver grains (e.g., Fig. 1 $A, B$, double arrows).

\section{Neuronal labeling with ${ }^{3} \mathrm{H}$-nipecotic acid}

Similar populations of radiolabeled neurons were present in corresponding layers of each of the three visual cortical areas examined. In layer II, radiolabeled neurons were generally small and round (Fig. 2A), while those in layer III were somewhat larger, plumper, and less prominently stained for Nissl substance
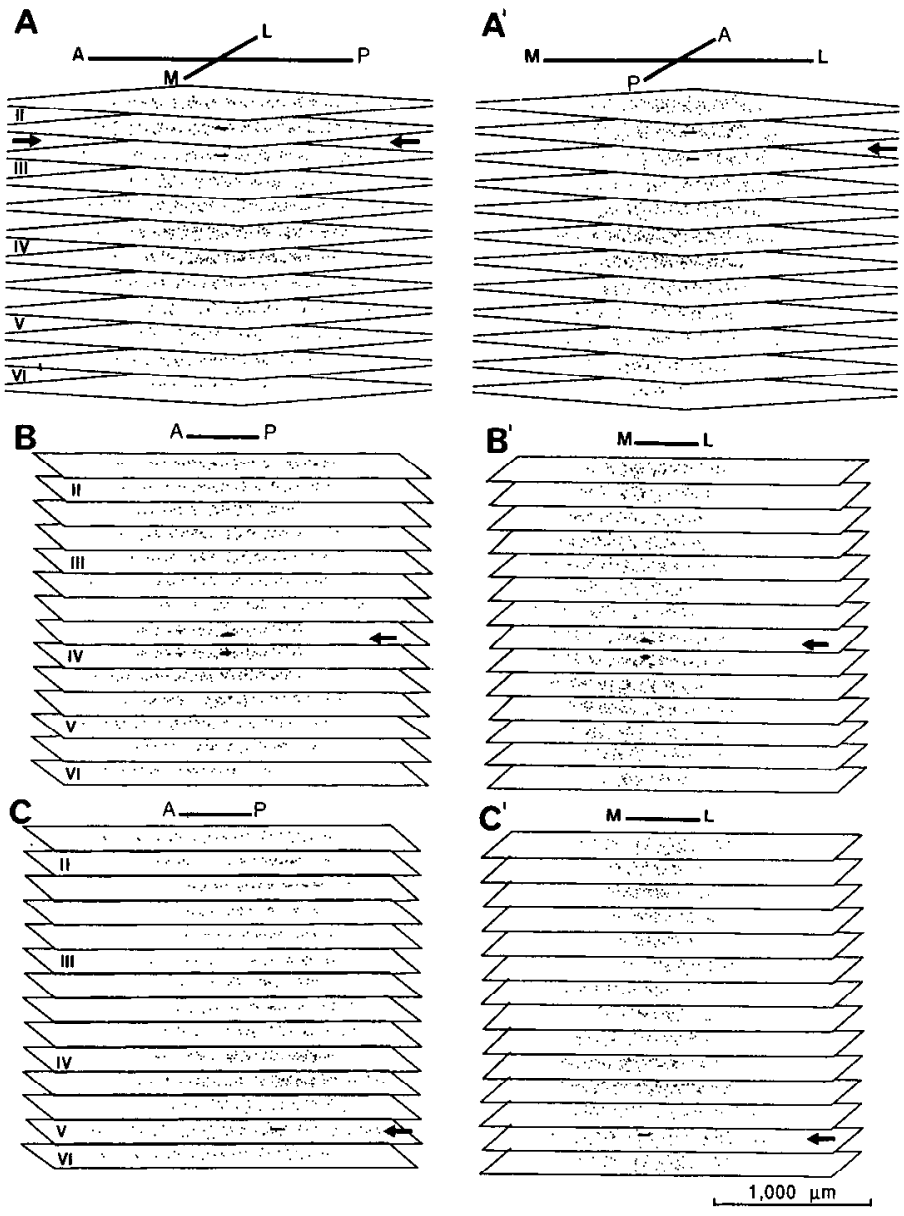

Figure 4. Three-dimensional pattern of retrogradely labeled neurons (small dots) in area V2: injections (shaded areas; see arrows) of ${ }^{3} \mathrm{H}-$ nipecotic acid (10 $\mathrm{nl}, 0.38 \mathrm{~mm})$ in supragranular $(A)$, granular $(B)$, and infragranular $(C)$ layers (see Fig. 3 caption). Prominent elongation of fields of labeling anteroposteriorly (marked $A-P$ ) and restriction mediolaterally (marked $M-L$ ) is common to all layers of V2. $A$, Layer-bylayer differences in the lateral spread of labeling produced by superficial injections are small. $B$, Injections placed in layer IV produce elliptical arrays of retrograde neuronal labeling of similar dimensions in all layers, with strongest labeling focused in infragranular layers. $C$, Injections of layer $\mathrm{V}$ produce a pattern that is the inverse of that of superficial injections; labeling is most widespread in infragranular layers (up to 1 $\mathrm{mm}$ ) and is diminished in radius (up to $0.6 \mathrm{~mm}$ ) and cell number in supragranular layers.

(Fig. 2B). Cells in both supragranular layers were distributed in loosely organized clusters that interdigitated with small zones of cortex (usually less than $200 \mu \mathrm{m}$ across) in which few or no radiolabeled neurons were present (e.g., see Figs. $8 C, D ; 10 a, a^{\prime}, a^{\prime \prime}$ ). Labeling in layer IV of areas V2 and V4 (Fig. $2 C$ ), and sublayers IVA (Fig. $2 D$ ) and IVB (Fig. $2 E$ ) of Vl targeted the largest neurons and avoided the small pyramidal or spiny stellate neurons also present in these layers. In IVC of area V1 (Fig. 2F), however, both small- and medium-sized neurons were radiolabeled. Radiolabeled neurons in all subdivisions of layer IV were closely grouped together and appeared to be distributed more homogeneously in the tangential plane than cells in overlying supragranular layers (e.g., see Fig. $\left.10 b, b^{\prime}, b^{\prime \prime}\right)$. Radiolabeled neurons in layers V (Fig. $2 G$ ) and VI (Fig. $2 H$ ) corresponded to both small- and medium-sized cells. Like supragranular layers, ${ }^{3} \mathrm{H}$-nipecotic acid labeling in layers $\mathrm{V}$ and VI corresponded to loosely organized clusters of radiolabeled somata separated by 
small, irregularly shaped zones largely free of labeling that were no larger than 200-300 $\mu \mathrm{m}$ across.

\section{Three-dimensional distributions of neurons labeled by ${ }^{3} \mathrm{H}$-nipecotic acid}

Injections of ${ }^{3} \mathrm{H}$-nipecotic acid targeting specific cortical layers produced markedly different three-dimensional patterns of retrograde labeling. When compared across visual areas, injections placed in corresponding layers produced patterns of labeling that, although sharing in some basic features, were always distinguished by either dimension or laminar patterning. We describe separately the precise intra- and interlaminar patterns of labeling produced from injections centered within specific cortical layers. Retrograde labeling from comparable injections in areas $\mathrm{V} 1, \mathrm{~V} 2$, and $\mathrm{V} 4$ is described together to highlight the differences and similarities that mark specific sets of intrinsic inhibitory circuits in these visual cortices.

Injections in supragranular layers. Injections placed at all depths within layers I, II, and III of V1 $(n=11$; e.g., Fig. $3 A, B)$, V2 $\left(n=5\right.$; Fig. $\left.4 A, A^{\prime}\right)$, and V4 $\left(n=6\right.$; Fig. $\left.5 A, A^{\prime}, C, D\right)$ produced the most widespread lateral labeling in layers I, II, and III. Importantly, in layer I not all neurons within the circumference of retrograde transport were labeled, indicating that labeling was not a conscquence of passive spread and somal uptake of the tracer along the pial surface. In V1, circularly symmetric fields of labeling extending some $1.0-1.5 \mathrm{~mm}$ from the injection center were found in all three supragranular layers (e.g., compare Fig. $3 A, A^{\prime}$ ). In area $\mathrm{V} 2$, however, distinctly elliptical fields of labeling were present (e.g., compare Fig. $4 A, A^{\prime}$ ). In layer II, the long axis of labeling was $0.7-0.9 \mathrm{~mm}$ and in layer III the long axis was 0.9-1.4 $\mathrm{mm}$; the short axis of labeling in both layers extended $0.5-0.6 \mathrm{~mm}$ from the central axis of the injection. The unique geometry of cell labeling in superficial cortical layers of V2, and indeed infragranular layers as well (see below and also Fig. $4 B, B^{\prime}, C, C^{\prime}$ ), was strongly reminiscent of the rostrocaudally oriented $C O$ stripes of this region. Finally, in area V4, circular fields of labeling in supragranular layers reached a lateral distance of 1.3-1.7 mm from the center of the injection site (e.g., compare Fig. $5 A, A^{\prime}$ ). In all three areas, small neuronal somata, almost obscured by their dense accumulations of silver grains, were clustered about the center of the injection, while larger neurons invested with more modest labeling predominated farther from the center. In areas V1 and V4, these most heavily labeled neurons occupied small circular fields, some $0.3-0.4 \mathrm{~mm}$ and $0.3-0.5 \mathrm{~mm}$ in diameter, respectively. In keeping with the distinctive geometry of cell labeling in V2, however, cells most heavily invested with silver grains in this area were distributed up to $0.5 \mathrm{~mm}$ from the injection center along the anteriorposterior axis, but were more narrowly focused mediolaterally.

Retrograde labeling in granular and infragranular layers was circumscribed relative to supragranular layers. In V1, the lateral displacement of labeled neurons in layer IV decreased in a graded fashion from lower aspects of layer III, where a maximal lateral distance of about $0.5-0.7 \mathrm{~mm}$ was observed, through layer IV, to layer IVCB where radiolabeled neurons were never more than about $0.25 \mathrm{~mm}$ lateral to the central axis of the injection. Below, in layers V and VI radiolabeling was sparse; in layer $V$ retrogradely labeled neurons were arrayed in small circular fields within $0.3 \mathrm{~mm}$ of the axis of the injection (although some outlying cells strayed as far as $0.6 \mathrm{~mm}$ ), while in layer VI all cells were confined within $0.25 \mathrm{~mm}$ of the central axis of the injection (Fig. $3 A, B$ ). In area $\mathrm{V} 2$, the radius of cell
A

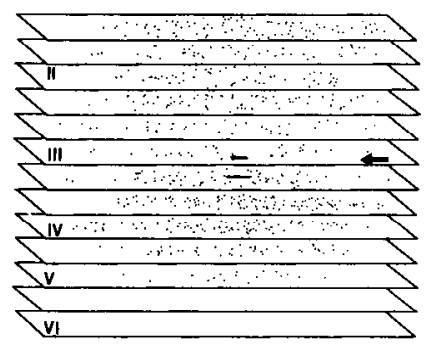

B

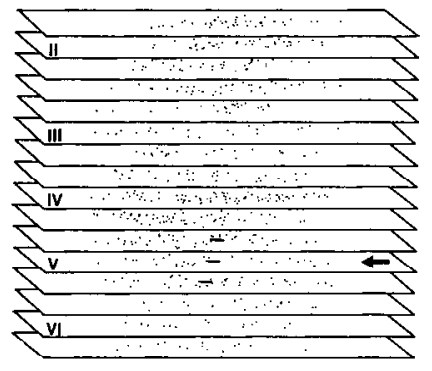

$\mathbf{A}^{\prime}$

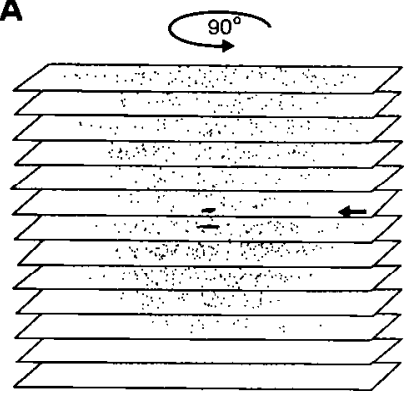

B'

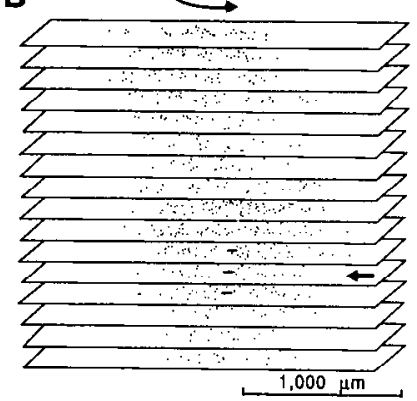

c
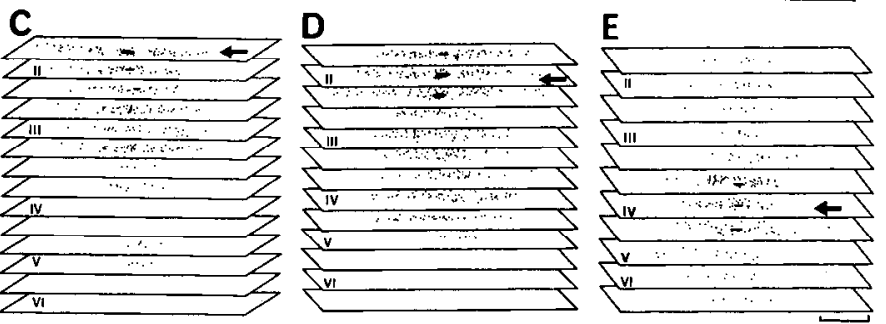

Figure 5. Three-dimensional distributions of neurons (small dots) retrogradely labeled following injection (shading; see arrows) of ${ }^{3} \mathrm{H}$-nipecotic acid in V4 ( $A$ and $B, 10 \mathrm{nl} ; C-E, 5 \mathrm{nl} ; 0.38 \mathrm{~mm}$ ). Rotation of individual reconstructions through $90^{\circ}\left(A, A^{\prime} ; B, B^{\prime}\right)$ demonstrates approximate circular symmetry in distribution of radiolabeled neurons. Injections in upper layer II $(C)$ produce retrograde labeling mainly in layers I, II, III, and upper V, while injections spreading into layer III $(B, E)$ produce labeling in layers I-upper V. All superficial injections produced widespread labeling in supragranular and (when present) granular layers (up to $0.8-1.5 \mathrm{~mm}$ ), with only small numbers of centrally located neurons labeled in upper layer $\mathrm{V}$. Injection in layers IV and/or $\mathrm{V}(B, E)$ produces regular, cylindrical arrays of labeled neurons through all layers.

labeling also decreased in granular and infragranular layers, albeit to a lesser extent. In layer IV, for example, radiolabeled neurons were generally confined within a roughly circular field with a radius of $0.7-0.8 \mathrm{~mm}$, while in layer $\mathrm{V}$, the elliptical pattern of labeling characteristic for $\mathrm{V} 2$ resumed, with labeled neurons extending $0.5-0.7 \mathrm{~mm}$ anterior-posterior from the injection center, and about $0.3-0.4 \mathrm{~mm}$ mediolaterally. In layer VI, most neurons were oriented along a short line $(0.5-0.6 \mathrm{~mm}$ in total length) running along the anterior-posterior direction, with few cells straying mediolaterally (Fig. 4A).

For the most part, cell labeling in infragranular layers of $\mathrm{VI}$ and V2 was light, that is, few neurons were labeled, and those that were labeled were invested with low densitics of silver grains. However, it is important to note that injections specifically spanning the border between layers II and III (e.g., Figs. $3 B, B^{\prime} ; 6 A$, large dots; $6 C, D$, large arrows) produced discrete numbers of very heavily labeled neurons in upper layer $\mathrm{V}$; these same injections also gave rise to a second group of strongly labeled cells in upper layer VI of area V1 (Figs. 3B, large dots; 


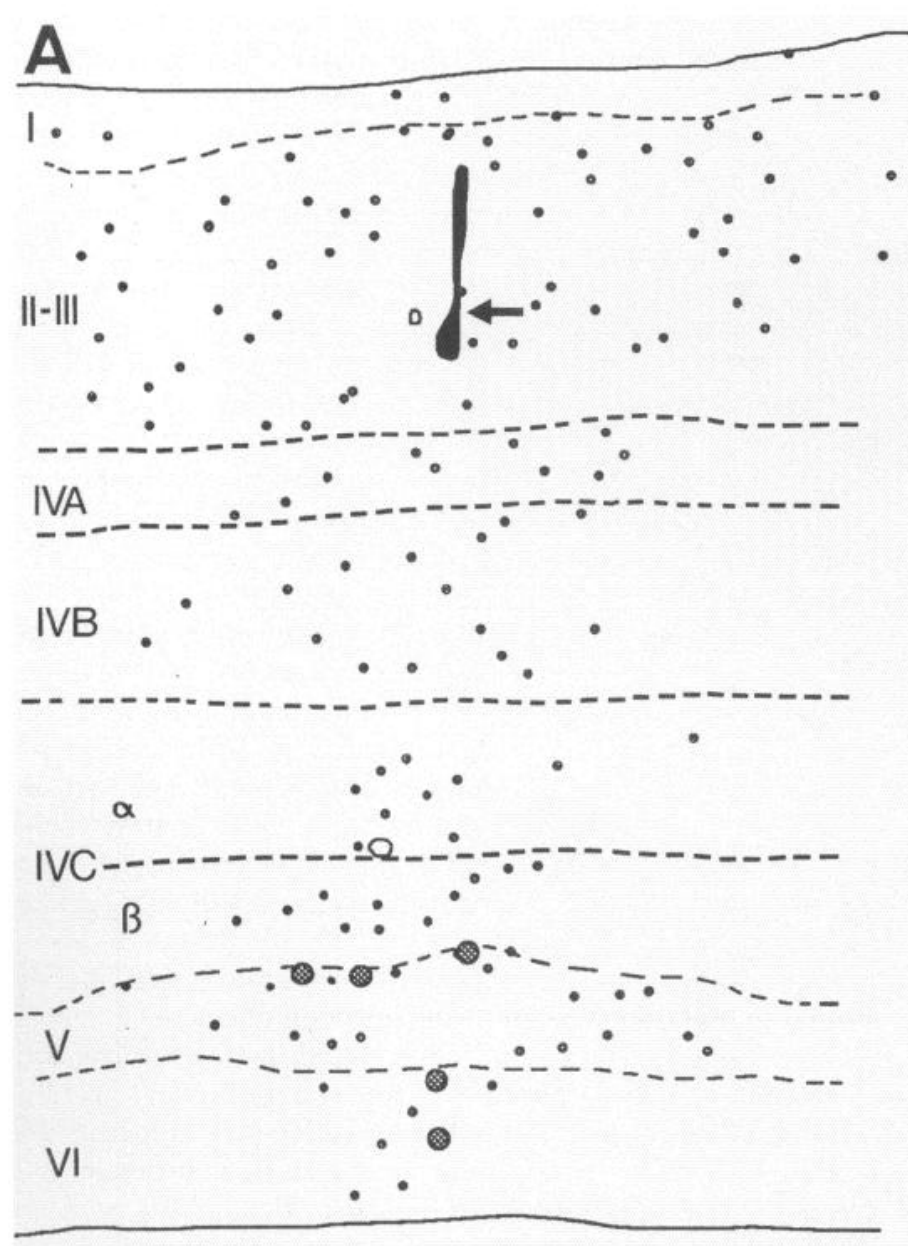

B
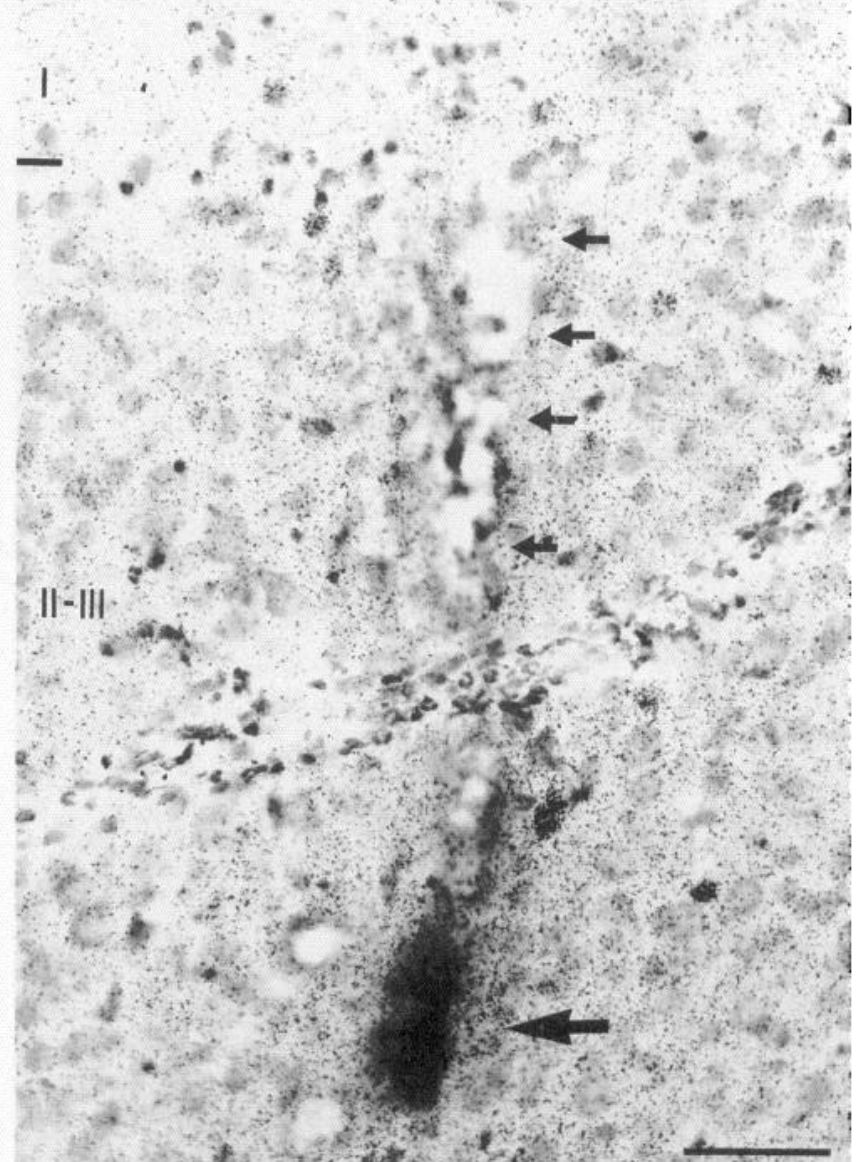

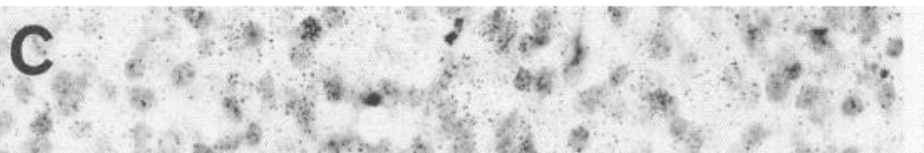

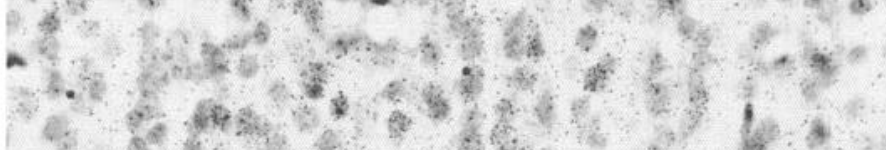

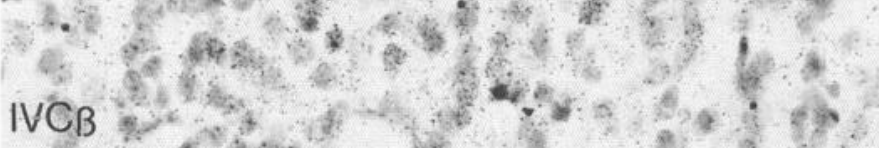

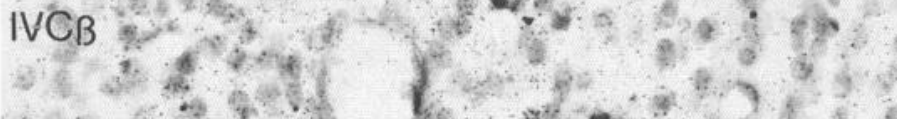

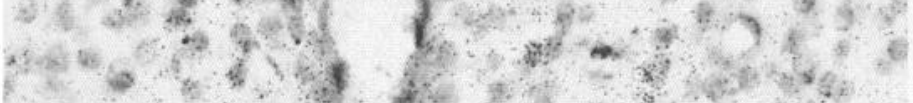

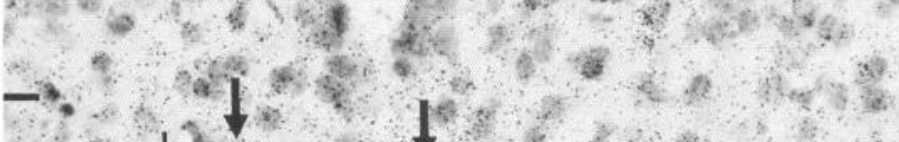

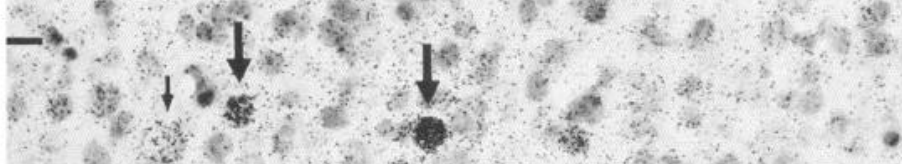

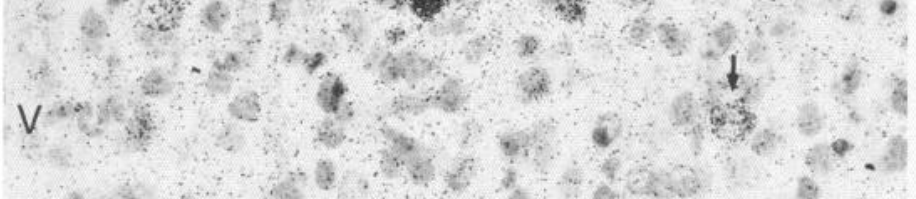

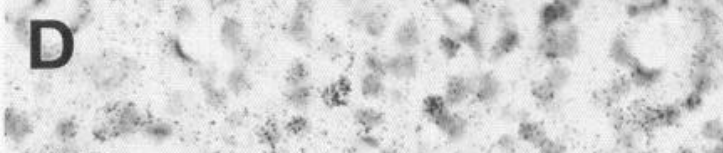

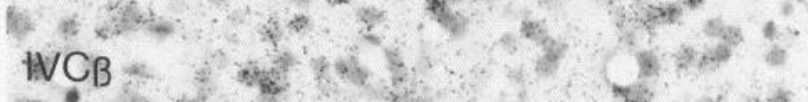

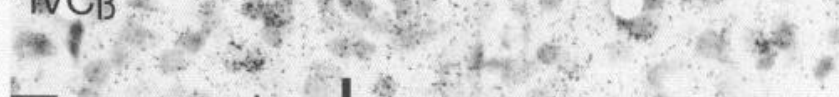
$-1+1+1+a$

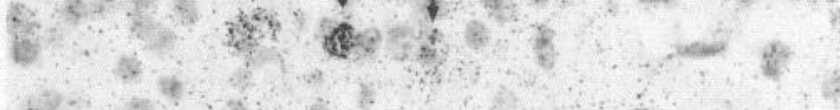

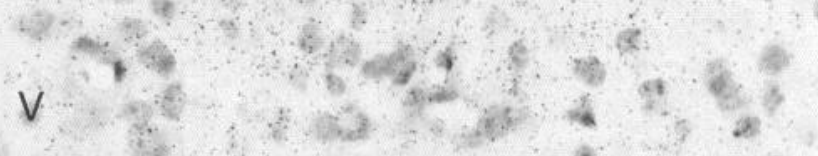
$-x^{4}+10+e^{2}, 6=0$ 7. 4 a $38 y^{3}$ as

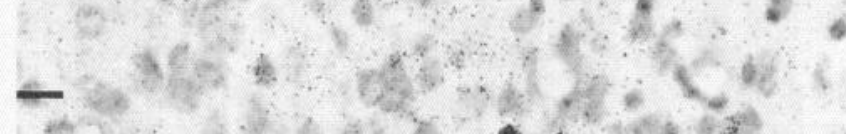

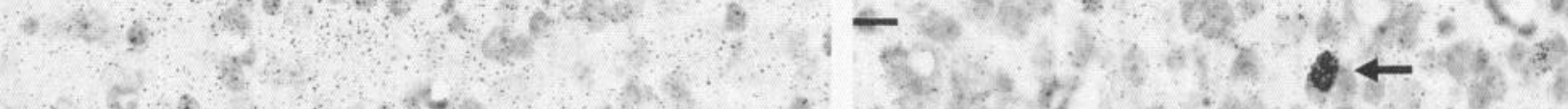

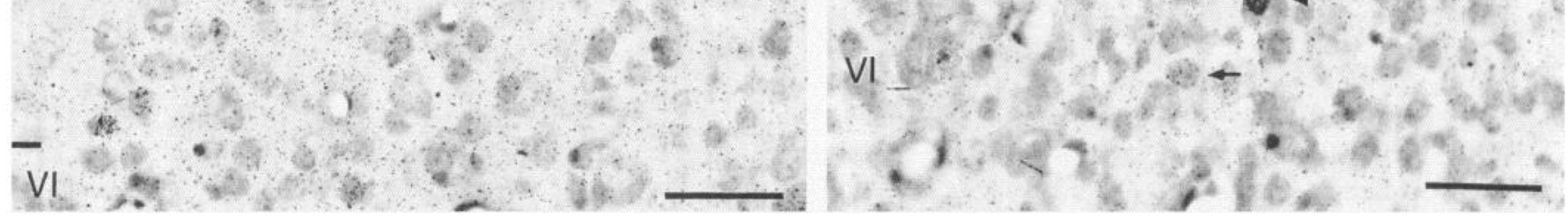


$6 A$, large dots; $6 C, D$, large arrows), while in $\mathrm{V} 2$ there was no evidence of a second stratum of heavily labeled neurons projecting superficially.

The precise placement of the injection also had important consequences for the patterning of retrograde labeling in granular and infragranular layers of area $\mathrm{V4}$, where strong laminar selectivity of labeling was observed (e.g., Fig. $5 A, A^{\prime}, C, D$ ); in this area alone the exact placement of injections at specific depths dictated not only the lateral extent of label, but also its presence or absence. Injections placed in upper layer II $(n=2$; e.g., Fig. $5 C$ ), for example, yielded labeling in layers I, II, III, and upper $\mathrm{V}$, but none in layers IV, lower $\mathrm{V}$, and VI, while injections placed more deeply in layers II and III $\left(n=4\right.$; e.g., Fig. $\left.5 A, A^{\prime}, D\right)$ produced labeling in layers I through upper $\mathrm{V}$, with no appreciable label in lower layer V and layer VI. The transition between layers in which radiolabeled neurons were or were not present was abrupt. In laycr $\mathrm{V}$, for cxamplc, ncuronal labcling remained strong in sections dorsally adjacent to those in which labeling was absent. When present, however, radiolabeled neurons in layer IV did not extend beyond $0.8-0.9 \mathrm{~mm}$ from the axis of the injection, and labeling in the top of layer $V$ remained within $0.7-0.8 \mathrm{~mm}$ from the injection center; no labeling was ever observed below this level. Retrograde labeling associated with supragranular injections in V4 was thus also unique in that no strongly labeled neurons stood out in deep cortical layers, as was the case for injections placed at the II/III border in V1 and V2.

Injections in granular layers. Area $\mathrm{V} 1$ is distinguished cytoarchitectonically foremost by prominent sublaminar organization in layer IV. Injections of ${ }^{3} \mathrm{H}$-nipecotic acid in the specific subdivisions that make up layer IV in area V1 produced distinctive patterns of labeling (compare Fig. $3 C, D$ ). The thinness of sublayer IVA, however, precluded its injection in isolation, and injections that involved lower layer III and IVA gave rise to patterns of labeling that were indistinguishable from those of injections confined to layer III. Because these injections encroached upon both layers III and IVA, it is uncertain whether any specific aspects of this pattern arose from neurons whose terminals were located in IVA, or whether layer IVA comes under the control of inhibitory circuits similar to those of layer III.

Following injection of layer IVB $(n=5$; e.g., Fig. $3 C)$, labeled neurons in layers I, II, and III of V1 were found up to 1.0-1.2 $\mathrm{mm}$ lateral to the axis of the injection. Within these layers, small, densely labeled cells predominated near the central axis of the injection, while larger and more weakly labeled cells occupied lateral positions. In layer IV, neuronal labeling remained laterally dispersed. In IVA, for example, labeled neurons were found up to $0.8-1.0 \mathrm{~mm}$ from the central axis of the injection. As in other layers, the most heavily labeled cells were located along the injection axis.

Labeling in layer IVB was similarly widespread. Importantly, however, whereas the intensity of label over single cells in all other layers and, indeed, associated with all other injection sites diminished with eccentricity, in layer IVB a single row of very heavily labeled neurons consistently marked the lateral margins of the fields of retrograde labeling, some $0.8-1.2 \mathrm{~mm}$ from the center of the injection (e.g., Figs. $3 C$, large dots; $7 A$, large dots; $\left.7 a^{\prime}-c^{\prime}\right)$. These striking neurons were among the largest cells in this layer (Fig. $7 a^{\prime}-c^{\prime}$ ) and showed no obvious clustering or concentration along any given radial axis (e.g., Figs. $3 C, 7 A$ ). Immediately below layer IVB, the lateral extent of retrograde labeling contracted. Labeled neurons in layers IVC and V were generally found within $0.5-0.8 \mathrm{~mm}$ of the central axis of the injection, while in layer VI the radius of labeling did not exceed $0.4-0.6 \mathrm{~mm}$.

Injections in layer IVC of area V1 produced a narrow, cylindrical array of radiolabeled neurons spanning all cortical layers ( $n=4$; e.g., Fig. 3D). Even adjacent to the zone of tracer uptake, labeled neurons in layer IVC did not stray beyond $0.2-0.4 \mathrm{~mm}$ from the presumed injection center. Within this radius, however, large numbers of heavily labeled, small- and mediumsized neurons were densely packed. A comparable radius of cell labeling was present in infragranular layers, within which relatively large numbers of somewhat more loosely packed but strongly labeled neurons were present. In sharp contrast, however, an equal circumference of labeling in supragranular layers encircled only small numbers of relatively weakly labeled neurons.

Highly regular layer-by-layer patterns of retrograde labeling, similar to that observed following injection of layer IVC of area V1, were also typical of injections placed in granular layers of extrastriate visual areas. In V2, somewhat elliptical fields of labeling in layers I-VI extended up to $0.6-0.8 \mathrm{~mm}$ from the injection center along the anterior-posterior coordinate, and $0.3-0.4 \mathrm{~mm}$ mediolaterally $\left(n=2\right.$; e.g., Fig. $\left.4 B, B^{\prime}\right)$, while in $\mathrm{V} 4$, injections placed mainly within layer IV produced a regular column of labeling in layers I-V extending $0.8-1.0 \mathrm{~mm}$ laterally, with very little labeling in layer VI ( $n=2$; e.g., Fig. $5 E)$. As in V1 (IVC), labeling of individual neurons in extrastriate areas tended to be heaviest in granular and infragranular layers, and layer IV was distinguished by a conspicuous increase in the areal density of radiolabeled neurons. In addition, all layers showed a strong center-to-peripheral gradient in the strength of labeling over individual cells; the most strongly labeled somata in layers II, III, V, and VI of area V2 occupied anterior-posteriorly elongated fields, whereas labeling of the central population of neurons in layer IV of V2 and in all layers of V4 more closely corresponded to a circle.

Injections in infragranular layers. Injection sites that invaded layers $\mathrm{V}$ and $\mathrm{VI}$ in $\mathrm{V} 1(n=2), \mathrm{V} 2(n=2)$, and V4 $(n=2)$ gave rise to patterns of retrograde labeling that were very nearly the mirror image of those produced by supragranularly placed injections. Thus, in all three areas, labeling reached a maximum lateral extent in layers $\mathrm{V}$ and VI. In area V1 (based on data obtained from one horizontally and one coronally sectioned site), neurons were found as far as $0.7-0.9 \mathrm{~mm}$ laterally from the central axis of the injection in layers $\mathrm{V}$ and VI. In V2,

Figure 6. Radial and lateral distribution of ${ }^{3} \mathrm{H}$-nipecotic acid-labeled cells in V1. $A$, Partial reconstruction made from three coronal sections. Injection site (blackened region, arrow; $5 \mathrm{nl}, 0.38 \mathrm{~mm}$ ) involves layers II and III. Note the characteristic lateral spread of labeling in layers II/III, and narrow array of labeling in layers IV-VI. $B$, In tissue sections, the injection site in $A$ appears as a dense accumulation of silver grains (large arrow). The capillary tract (small arrows) is sometimes also visible. This injection produced small numbers of very heavily labeled neurons in the tops of layers V $(A$, large dots; $C$ and $D$, large arrows) and layer VI ( $A$, large dots; $D$, large arrow). These neurons stand out from all other radiolabeled neurons in the same layers (e.g., small arrows). Scale bars, $50 \mu \mathrm{m}$. 

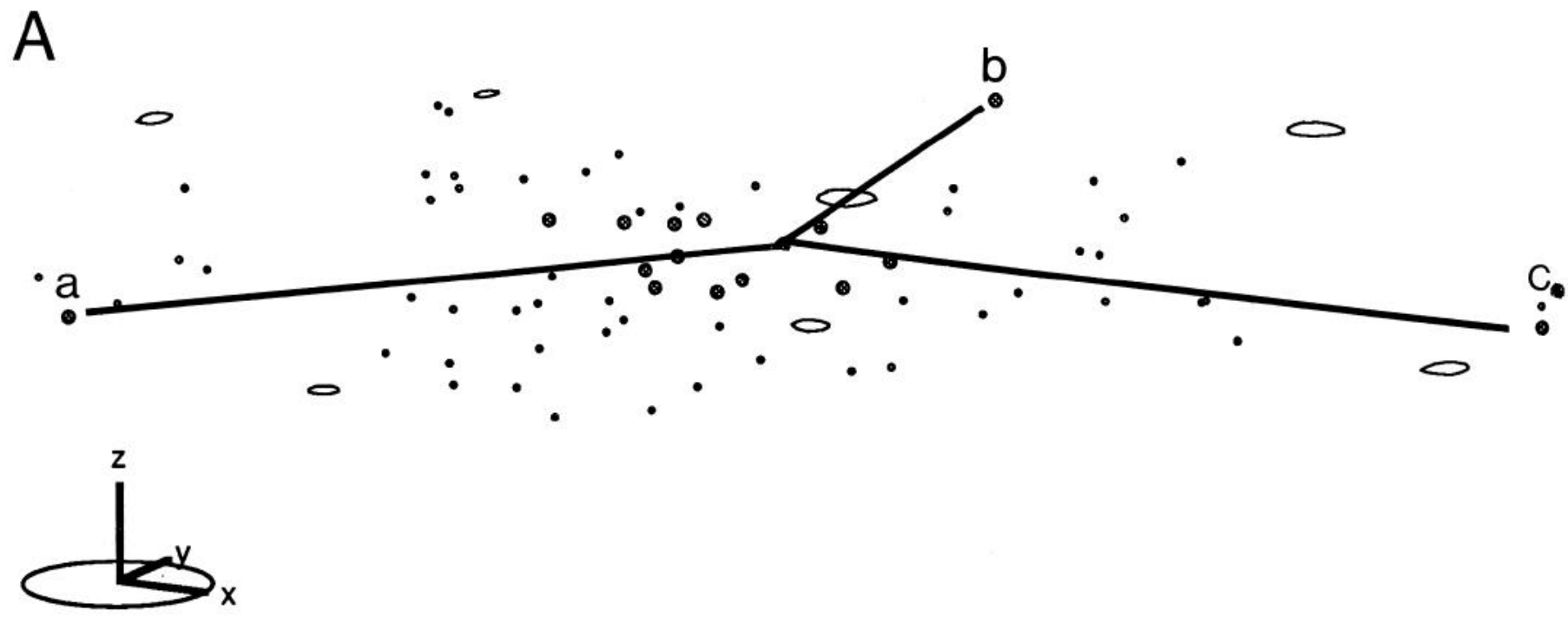

Rotn. $30^{\circ}$ Tilt $15^{\circ}$
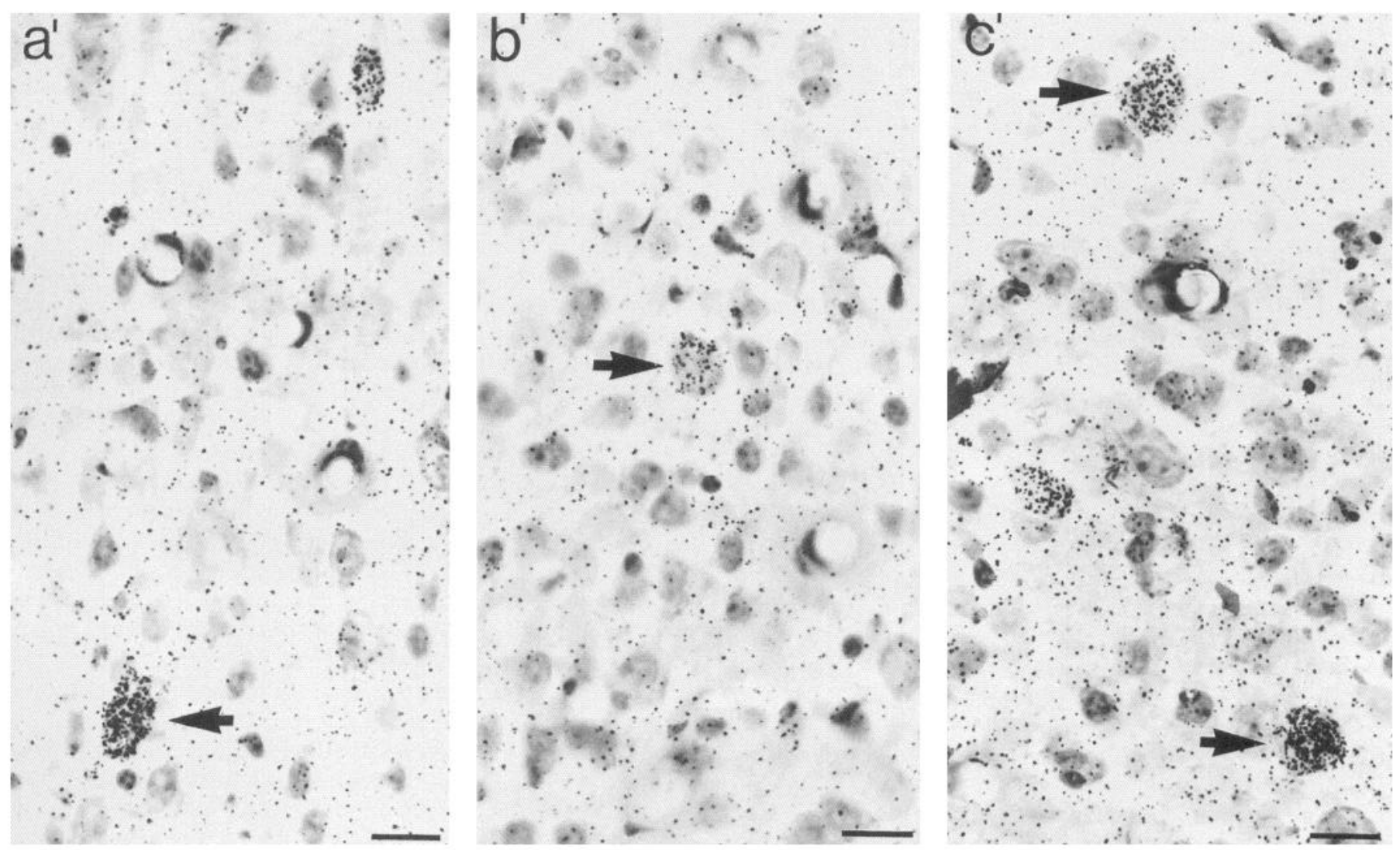

Figure 7. Long lateral projections in layer IVB. A, Tilted view of the pattern of strongly (large dots) and more moderately labeled (small dots) neurons following injection of ${ }^{3} \mathrm{H}$-nipecotic acid $(10 \mathrm{nl}, 0.38 \mathrm{~mm})$ in the same layer. In addition to a typical accumulation of strongly labeled cells in proximity to the injection site (large central dots), a conspicuous group of heavily labeled neurons (large dots at positions $a-c$ ) are also found about $1 \mathrm{~mm}$ from the injection site. These cells (arrows, $a^{\prime}-c^{\prime}$ ) are among the largest neurons of layer IVB; their heavy labeling contrasts with the moderate to weak labeling of other neurons. Scale bars, $20 \mu \mathrm{m}$.

radiolabeled neurons in layers V/VI were distributed up to 1.0 $1.1 \mathrm{~mm}$ from the injection site along the anterior-posterior axis, and remained within $0.4-0.7 \mathrm{~mm}$ orthogonally (e.g., Fig. $4 C, C^{\prime}$ ), while in area V4 labeled neurons were diffusely scattered within a $0.7-0.8 \mathrm{~mm}$ radius of the center of the injection in layer $\mathrm{V}$ and within $0.4-0.6 \mathrm{~mm}$ of the axis of the injection in layer VI (e.g., Fig. 5B).

The radius of cell labeling diminished for all three areas in granular and supragranular cortical layers. In V1, layers IVB and IVC showed retrograde labeling only found as far as 0.6- 


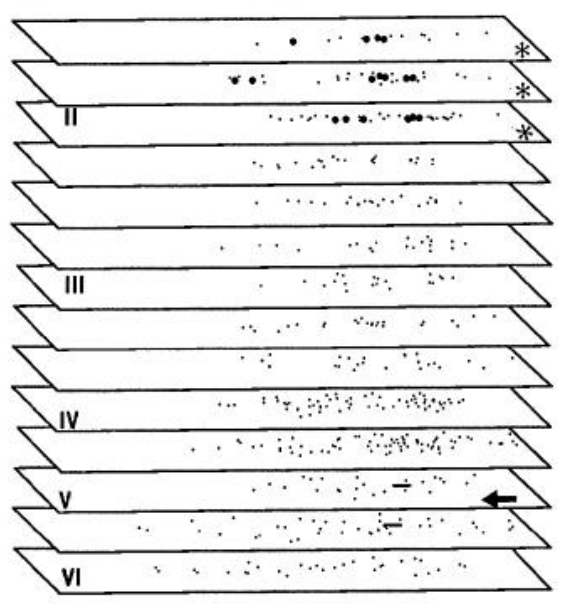

B
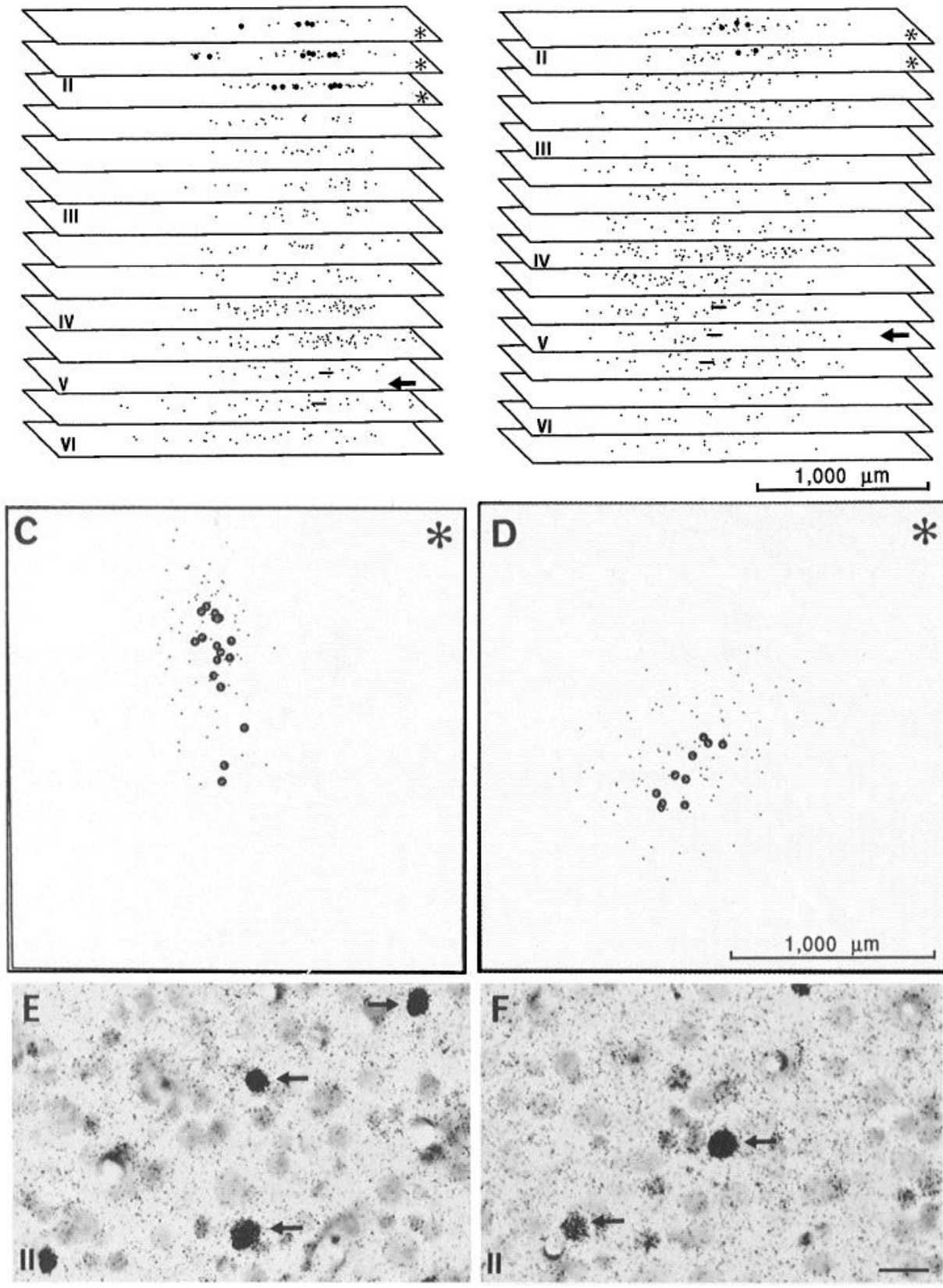
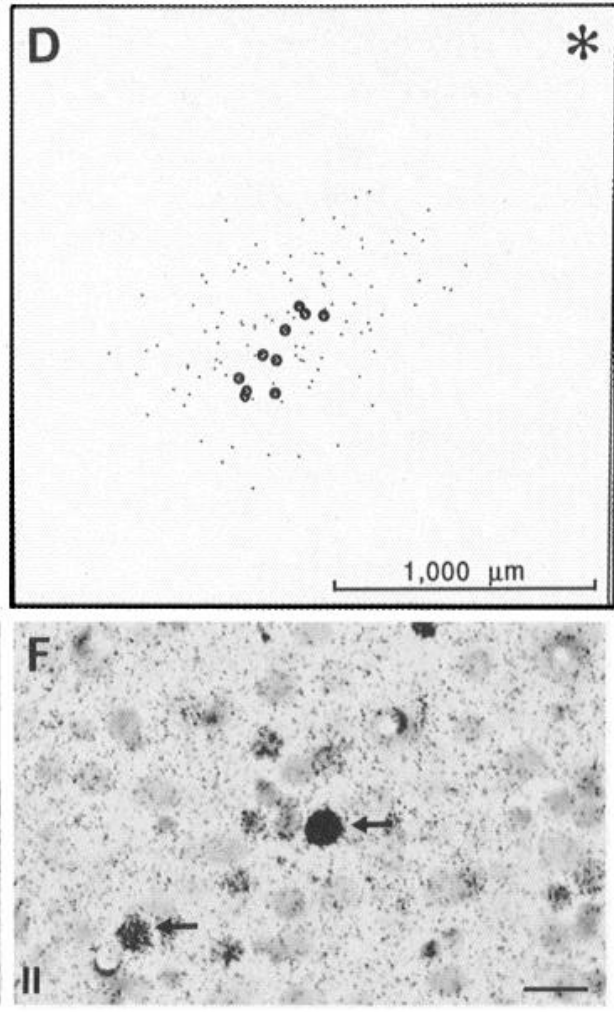

Figure 8. Radial and tangential distribution of ${ }^{3} \mathrm{H}$-nipecotic acid-labeled cells in areas V2 and V4. Injections (10 $\mathrm{nl}, 0.38 \mathrm{~mm}$; see arrows) in layer $\mathrm{V}$ produce laterally dispersed labeling in infragranular and granular layers, and more circumspect and generally weak labeling of supragranular cortical layers. Small populations of very strongly labeled neurons in layer II ( $A$ and $B$, large dots) are found specifically in conjunction with layer $\mathrm{V}$ injections. $C$ and $D$, Superimposition of sections containing these cells ( $A$ and $B$, asterisks) shows that the distribution of very darkly labeled layer II neurons (large dots) forms an ellipse, elongated along the anterior-posterior axis in V2 $(C)$, but is more circular in V4 $(D)$. The neurons belonging to these select groups $(E$, area $\mathrm{V} 2$, arrows; $F$, area V 4 , arrows) are only a small subpopulation of labeled cells. Scale bars for $E$ and $F, 20 \mu \mathrm{m}$.
$0.7 \mathrm{~mm}$ lateral to the axis of the injection, and in layers IVA, II, and III, cells were few in number and confined to a narrow column, some $0.4-0.5 \mathrm{~mm}$ across. Similarly, in V2 a fairly high density of labeled neurons was packed within a circular field extending some $0.5 \mathrm{~mm}$ lateral to the axis of the injection in layer IV, while in layers II and III sparsely labeled neurons extended up to $0.7 \mathrm{~mm}$ along the anterior-posterior axis and $0.2-0.5 \mathrm{~mm}$ mediolaterally (e.g., Fig. $4 C, C^{\prime}$ ). In V4, similar circular fields of labeling some $0.7 \mathrm{~mm}$ and $0.4-0.8 \mathrm{~mm}$ in diameter were present in layers IV and II/III, respectively (e.g., Fig. $5 B, B^{\prime}$.

For the most part, the silver grain density over individual neurons occupying supragranular layers was light. However, in all three areas, the uniformity of the light and diffuse labeling in superficial cortical layers was interrupted by small popula- tions of exceptionally heavily labeled neuronal somata in layer II (e.g., Figs. $8 A-D$, large dots; $8 E, F$, arrows). In areas V1 and $\mathrm{V} 4$, these small but striking populations of neurons were clustered directly over the axis of the injection (e.g., Fig. $8 B, D$ ). In area V2, however, analogous sets of neurons stretched along the anterior-posterior axis, forming a straight and narrow line passing through the injection center (e.g., Fig. $8 A, C$ ). The very heavy labeling of these discrete cell populations provided a striking contrast to other radiolabeled neurons in the same layer that contained many fewer silver grains (e.g., Fig. $8 E, F$ ).

\section{Relationship of ${ }^{3} \mathrm{H}$-nipecotic acid labeling to $\mathrm{CO}$}

In addition to laminar distribution, labeling of inhibitory neurons associated with injections in areas V1 and V2 was assessed in relation to the $\mathrm{CO}$ compartments (blobs and interblobs of 

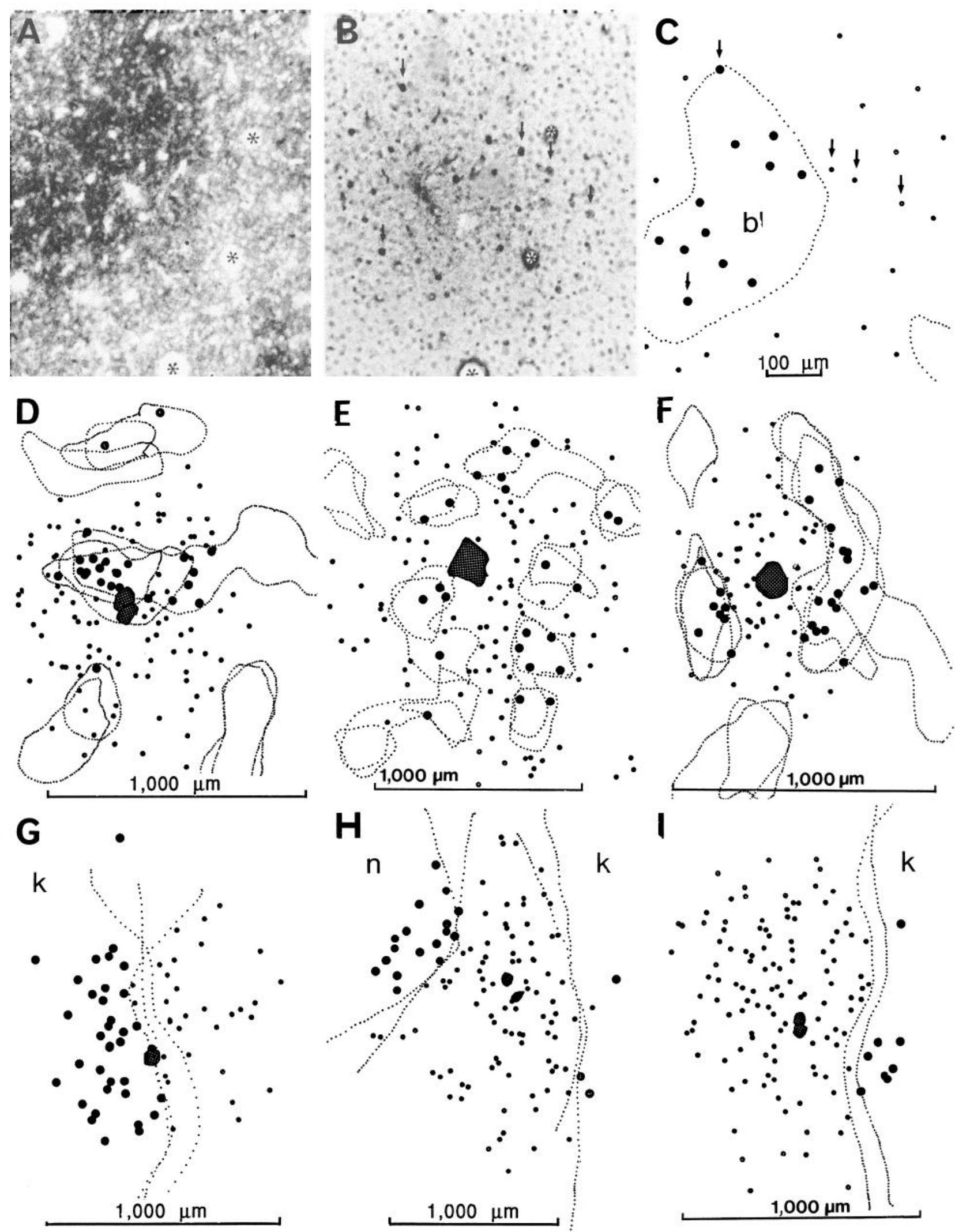

Figure 9. Patterns of $\mathrm{CO}$ activity (e.g., A) and distributions of ${ }^{3} \mathrm{H}$-nipecotic acid-labeled neurons on adjacent sections (e.g., B). Asterisks mark the same capillaries. Superimposed tracings $(C)$ reveal the relationship between radiolabeled neurons and CO compartments of areas $\mathrm{Vl}(C-F)$ and V2 $(G-I)$ following injection $(5 \mathrm{nl}, 0.38 \mathrm{~mm})$. Neurons lying within the CO-rich blobs (e.g., $b l$ in $C)$ of V1 or within the thick $(k)$ or thin $(n)$ stripes of V2 are represented as large dots, neurons in interblobs of V1 and pale stripes of V2 correspond to small dots, and injection sites are marked as shaded areas. $D$. Injections near the border of blob and interblob regions produce roughly equivalent retrograde labeling of the two CO compartments. Labeling associated with injections that appear to lie within interblob regions $(E, F)$ is biased for this same compartment, although a proportion of the labeling invades blobs as well. $G$. Injections that straddle the boundaries between pale and thick stripes in V2 result in comparable labeling of both stripes. Injections that appear to be confined to pale stripes $(H, I)$ produce a pattern of retrograde labeling in which most radiolabeled neurons lie within the same stripe. However, small numbers of retrogradely labeled neurons occupy neighboring thick and thin stripes as well. 
layers II and III of area V1; thick, thin, and pale stripes of area V2) that characterize these cortices. This was achieved by superimposition of camera lucida drawings (e.g., Fig. $9 C$ ) of neuronal labeling (e.g., Fig. $9 B$ ) with those of patterns of $\mathrm{CO}$ activity obtained from adjacent sections (e.g., Fig. 9A).

Examination of labeling following injections centered within interblobs or blobs, or involving both compartments, revealed that the tangential organization of radiolabeled neurons in layers II and III was biased in relation to the location of the capillary tip with respect to $\mathrm{CO}$ compartments. For example, injections where the capillary tip and surrounding dense halo of silver grains were restricted to interblob zones $(n=3)$ produced the majority of labeled neurons within CO-poor interblobs (e.g., Fig. $9 E, F)$. Only small numbers of labeled neurons were also found within nearby blobs (Fig. $9 E, F$, large dots). Conversely, injections that were centered mainly within blobs $(n=4)$ produced a pattern of labeling in which radiolabeled neurons were in highest density within neighboring blobs. Again, however, intervening interblob regions always contained a few radiolabeled neurons. Injections that spread to both blob and interblob zones ( $n=4$; e.g., Fig. $9 D$ ) produced labeling that was more equally distributed among CO-rich and -poor regions.

The unique topography of the fields of neuronal labeling in V2 was also related to local CO organization; the orientation of the elongated fields of ${ }^{3} \mathrm{H}$-nipecotic acid labeling paralleled that of $\mathrm{CO}$ stripes. However, although labeling followed the contours of stripes, fields encompassing labeled neurons sometimes traversed their boundaries. Injections placed within pale stripes ( $n$ $=4$ ), for example, resulted in labeling that mainly occupied that stripe (e.g., Fig. 9H,I). Nonetheless, a small proportion of labeled neurons were always found within neighboring $\mathrm{CO}$-rich thick and/or thin stripes (Fig. 9H,I, large dots). Injections placed within the center of thick or thin stripes were not achieved in this series of injections. However, as might be expected, injections placed near the boundaries of pale and $\mathrm{CO}$-dense stripes ( $n=2$; e.g., Fig. $9 G$ ) produced roughly equal densities of labeled neurons in each compartment.

\section{Discussion}

In order to reveal inhibitory projections, we relied on autoradiographic detection of GABA-containing neurons radiolabeled following microinjection of ${ }^{3} \mathrm{H}$-nipecotic acid into specific layers of areas V1, V2, and V4. The selectivity of nipecotic acid as a potent competitor at high-affinity GABA uptake sites is well documented (e.g., Krogsgaard-Larsen and Johnston, 1975). Its specificity is also reflected in this study in the selective labeling of GABAergic neurons following microinjection of ${ }^{3} \mathrm{H}$-nipecotic acid in primate area V1 where, bar one cell, all radiolabeled neurons immunocytochemically tested were strongly GABA immunoreactive. In layer IVC, however, a very small proportion of cells may correspond to GABA-negative neurons. Following superficial injections of ${ }^{3} \mathrm{H}-\mathrm{GABA}$, a significantly higher proportion (66-91\%) of GABA-immunonegative neurons are radiolabeled in this layer (layer IVC) and in the top of layer $\mathrm{V}$ (Kisvarday et al., 1986a). However, in these investigations, although the concentration of radioligand used was similar to the present study, injections were 10-20 times larger. Injections of ${ }^{3} \mathrm{H}$-nipecotic acid ranging between 50 and $200 \mathrm{nl}$ have also been found to produce more extensive labeling of GABA-immunonegative neurons than was observed in the present study ( $Z$. F. Kisvarday, A. Cowey, and P. Somogyi, unpublished observations). Thus, there is potential for nonselective uptake of both
${ }^{3} \mathrm{H}$-nipecotic acid and ${ }^{3} \mathrm{H}-\mathrm{GABA}$. In the case of ${ }^{3} \mathrm{H}$-nipecotic acid, the degree of nonselectivity appears to depend, at least in part, on injection parameters, and with the injection concentrations, volumes, and delivery velocity used in the present study, uptake of ${ }^{3} \mathrm{H}$-nipecotic acid into GABA-immunonegative neurons is minimal or absent.

That GABAergic neurons were retrogradely labeled by ${ }^{3} \mathrm{H}-$ nipecotic acid is supported foremost by the distribution of labeled cells in relation to injection sites. The prominent anisotropies in the distribution of radiolabeled neurons in both horizontal and vertical directions discount simple diffusion and somatic uptake of the tracer. Dendritic uptake of this compound is also unlikely in view of the selectivity of ${ }^{3} \mathrm{H}$-nipecotic acid for GABAergic neurons or presumed GABAergic aspiny neurons whose dendritic arbors have been shown to be typically limited to one or two cortical layers (e.g., Kisvarday et al., 1986c; Lund, 1987; Lund et al., 1988; Lund and Yoshioka, 1991). Finally, radiolabeling by ${ }^{3} \mathrm{H}-\mathrm{GABA}$ distal from injection sites was eliminated in a previous study by pretreatment of monkeys with the axoplasmic transport inhibitor colchicine (DeFelipe and Jones, 1985), strengthening conclusions that cells were retrogradely labeled. By analogy, radiolabeling of neurons with ${ }^{3} \mathrm{H}$ nipecotic acid, which presumably occurs via the same uptake and transport mechanisms, is also almost certainly a product of retrograde transport.

\section{Relationship of ${ }^{3} \mathrm{H}$-nipecotic acid labeling to identified $G A B$ Aergic neurons}

The strength and distribution of radiolabeling of GABAergic neurons with ${ }^{3} \mathrm{H}$-nipecotic acid provide clues as to the location and degree of clustering of axonal ramifications in relation to the parent soma. Many of the patterns of axon terminations predicted by this labeling are consistent with descriptions of particular aspiny or sparsely spiny neurons identified in Golgi impregnation and single-cell injection studies and either presumed or immunocytochemically demonstrated to be GABAergic. The clutch cell, for example, whose axons generally ramify within several hundred micrometers of its cell body (e.g., Kisvarday et al., 1986c; Lund, 1987; Lund et al., 1988; Lund and Yoshioka, 1991), is a strong candidatc for the GABAergic neurons heavily radiolabeled in proximity to injection sites, particularly in layer IV. On the other hand, radiolabeled neurons found in layers II/III directly above deep injections very likely correspond to double bouquet cells, which are abundant in upper cortical layers, and whose axons traverse layers II-V in radially restricted bundles (Somogyi and Cowey, 1981; DeFelipe et al., 1990). The very heavily retrogradely labeled neurons in layer II following deep injections further suggest that a subpopulation of neurons with double-bouquet-like morphology issue descending axons whose terminals are mainly clustered in layers $\mathrm{V}$ and VI. Similarly, heavy ${ }^{3} \mathrm{H}$-nipecotic acid labeling in layers $\mathrm{V}$ and VI of V1 and V2 following injections at the border between layers II and III indicates that subsets of neurons with morphology similar to the double bouquet cell but sending axons upward, first described in early Golgi impregnation studies by Martinotti (1889) and Ramon y Cajal (1891) and more recently described in deep cortical layers of primate visual cortex (Lund, 1987; Lund et al., 1988; Lund and Yoshioka, 1991), send most of their axon terminals specifically to superficial cortical layers.

Lightly radiolabeled neurons lying lateral to the central axis of the injection are likely to correspond to basket cells. The light labeling, medium size, and plump appearance of these cells are 
consistent with the morphology and horizontally distributed axon terminals that identify these cells in Golgi or HRP injection experiments (e.g., Somogyi et al., 1983b; Lund, 1987; Lund et al., 1988; Lund and Yoshioka, 1991). Further, basket cells have also been shown to issue ascending or descending axon collaterals that span several cortical layers (Martin et al., 1983; Somogyi et al., 1983b; Lund et al., 1988; Lund and Yoshioka, 1991); this interlaminar collateral system may provide a means by which laterally situated, presumed basket cells can be labeled from injections of ${ }^{3} \mathrm{H}$-nipecotic acid in other than the host layer. The cells heavily labeled in IVB in area V1 up to $1 \mathrm{~mm}$ laterally from injection sites are probably also basket cells having laterally extensive axons, but distinguished by highly focused axon terminals rather than the divergent ramifications characteristic of all basket cells studied to date (Martin et al., 1983; Somogyi et al., 1983b; Lund, 1987; Lund et al., 1988; Lund and Yoshioka, 1991). Our findings indicate that this heavily labeled cell, unique to layer IVB of V1, accounts for a relatively small proportion of the smooth cells in this layer. It will be important to direct attention to this cell type and its postsynaptic relations, particularly in view of its suspected relevance for the generation of directional bias in cortical neurons (see below).

\section{Vertical organization of GABAergic connections}

Early Golgi impregnation studies revealed a wealth of neural connections between cortical layers (e.g., Ramon y Cajal, 1911; Lorente de No, 1922, 1938). More recently, a strong radial component of pyramidal cell organization has been confirmed in sensory and nonsensory cortices using Golgi impregnation (e.g., Lund and Boothe, 1975), degeneration (Szentagothai, 1965; Spatz et al., 1970; Nauta et al., 1973), or tract tracing (c.g., Hubel and Wiesel, 1972; Goldman and Nauta, 1977), and physiological findings provide evidence for a parallel functional organization (e.g., Mountcastle, 1957; Hubel and Wiesel, 1962).

Golgi impregnation studies in macaque primary visual cortex also provide evidence for strong radial components of axons of many types of smooth, presumed inhibitory neurons (e.g., Lund, 1987; Lund et al., 1988; Lund and Yoshioka, 1991). Not surprisingly, injection of ${ }^{3} \mathrm{H}$-nipecotic acid provides evidence for a prominent vertical component of intrinsic inhibitory cortical connections in both striate and extrastriate cortices. All injections in areas V1, V2, and V4, for example, produce radially extensive bands of strongest perikaryal labeling within narrow columns (200-500 $\mu \mathrm{m}$ in diameter) lying directly above and below injection sites. Interestingly, the area of cortex occupied by this heaviest ${ }^{3} \mathrm{H}$-nipecotic acid labeling in V1 falls within the range of a number of other columnar systems described for this area such as ocular dominance columns (Hubel and Wiesel, 1962), hypercolumns, defined as slabs of cortex within which all orientation preferences are represented (Hubel and Wiesel, 1974) and the discontinuous patches of intrinsic cortical connections identified following focal extracellular injections of HRP in V1 (Rockland and Lund, 1983; Livingstone and Hubel, 1984), V2 (Rockland, 1983), and V4 (Rockland, 1985). Although the vasculature of the cerebral cortex is also radially organized, it is unlikely that the columnar patterns of ${ }^{3} \mathrm{H}$-nipecotic acid labeling occur as a consequence of transport of the tracer in the blood since each area showed additional striking layer-by-layer differences in the strength and proportion of neuronal labeling.

Striking homologies are found among specific sets of vertically oriented inhibitory connections across areas. Injection of layers $\mathrm{V} / \mathrm{VI}$ in V1, V2, and V4, for example, revealed highly circum- scribed and focused inhibitory inputs to these layers that arise from select neuronal populations in layer II. Similar radial connections were reported in the sensorimotor cortex (DeFelipe and Jones, 1985) and primary visual cortex (Somogyi et al., $1981 \mathrm{a})$ of the rhesus monkey in tracing studies using ${ }^{3} \mathrm{H}-\mathrm{GABA}$. Areas $\mathrm{V} 1$ and $\mathrm{V} 2$ also shared strong inhibitory inputs to layers II/III from neurons in upper layer V; in V1, a second stratum of GABAergic neurons in layer VI contribute an additional highly directed input to this same superficial layer.

The columnar organization of inhibitory neurons in striate and extrastriate visual cortices does, however, show significant variation that is presumably related to functional specialization. For example, while all layers in areas V1 and V2 are linked by vertical inhibitory connections (see also Somogyi et al., 1981a, 1983a), the supragranular and granular layers of V4 are subject to a much more selective GABAergic influence (see Fig. 10). Injection of ${ }^{3} \mathrm{H}$-nipecotic acid in upper layer II, for example, produces labeling that avoids layers IV, lower V, and VI, while injections placed more deeply in layers II/III provide no evidence of inhibitory inputs arising from layers $\mathrm{V}$ and VI. Thus, the very heavy deep-to-superficial connections characterizing both areas V1 and V2 could not be demonstrated in V4. Previous studies using ${ }^{3} \mathrm{H}$-GABA have also provided evidence for differences in the interlaminar organization of inhibitory connections of sensorimotor versus primary visual cortex of the primate (DeFelipe and Jones, 1985), suggesting that areas involved in different functions are distinguished by intrinsic inhibitory connections. Thus, differences noted between visual areas V1 and V2 on the one hand and V4 on the other may be related to the physiological similarity of $\mathrm{V} 1$ and $\mathrm{V} 2$ and the cmcrgence of distinctive properties such as color constancy and selective attention in area V4 (see Gilbert, 1983; Zeki, 1983; Moran and Desimone, 1985).

\section{Horizontal organization of GABAergic connections}

Since the identification of extensive (up to $6 \mathrm{~mm}$ ) and prominently clustered horizontally directed excitatory connections, first observed with degeneration methods (e.g., Creutzfeldt et al., 1977; Fisken et al., 1975) and later revealed by intra- and extracellular injections of HRP (e.g., Gilbert and Wiesel, 1979, 1983; Rockland and Lund, 1983; Livingstone and Hubel, 1984; Martin and Whitteridge, 1984), the question has arisen of whether similar long-range inhibitory connections also exist. Physiological studies using techniques of cross-correlation have produced evidence of lateral inhibitory cortical connections extending up to $700 \mu \mathrm{m}$ in the cat (Toyama et al., 1981; Hata et al., 1988). In the present study, however, injection of ${ }^{3} \mathrm{H}$-nipecotic acid produces retrogradely labeled cells up to $1.5-1.7 \mathrm{~mm}$ lateral from injection sites in area V4, and connections of up to 1-1.5 $\mathrm{mm}$ in V1. Similar values have been obtained in V1 using ${ }^{3} \mathrm{H}$ GABA in area 17 of macaques (Somogyi et al., 1981a, 1983a). It should be emphasized, however, that identification of synaptic interactions in cross-correlation studies and retrograde labeling with ${ }^{3} \mathrm{H}$-nipecotic acid or ${ }^{3} \mathrm{H}-\mathrm{GABA}$ each depend on the number of terminals individual cells maintain in proximity to recording or injection sites. Thus, values obtained from these studies may underestimate the horizontal extent of inhibitory connections whose lateralmost terminals may be sparse. Nonetheless, values obtained in the present study are close to results from analyses of injected and Golgi-impregnated smooth cells, where the most widespread lateral inhibitory connections, made by the horizontal branches of basket cell axons, have been found to reach 

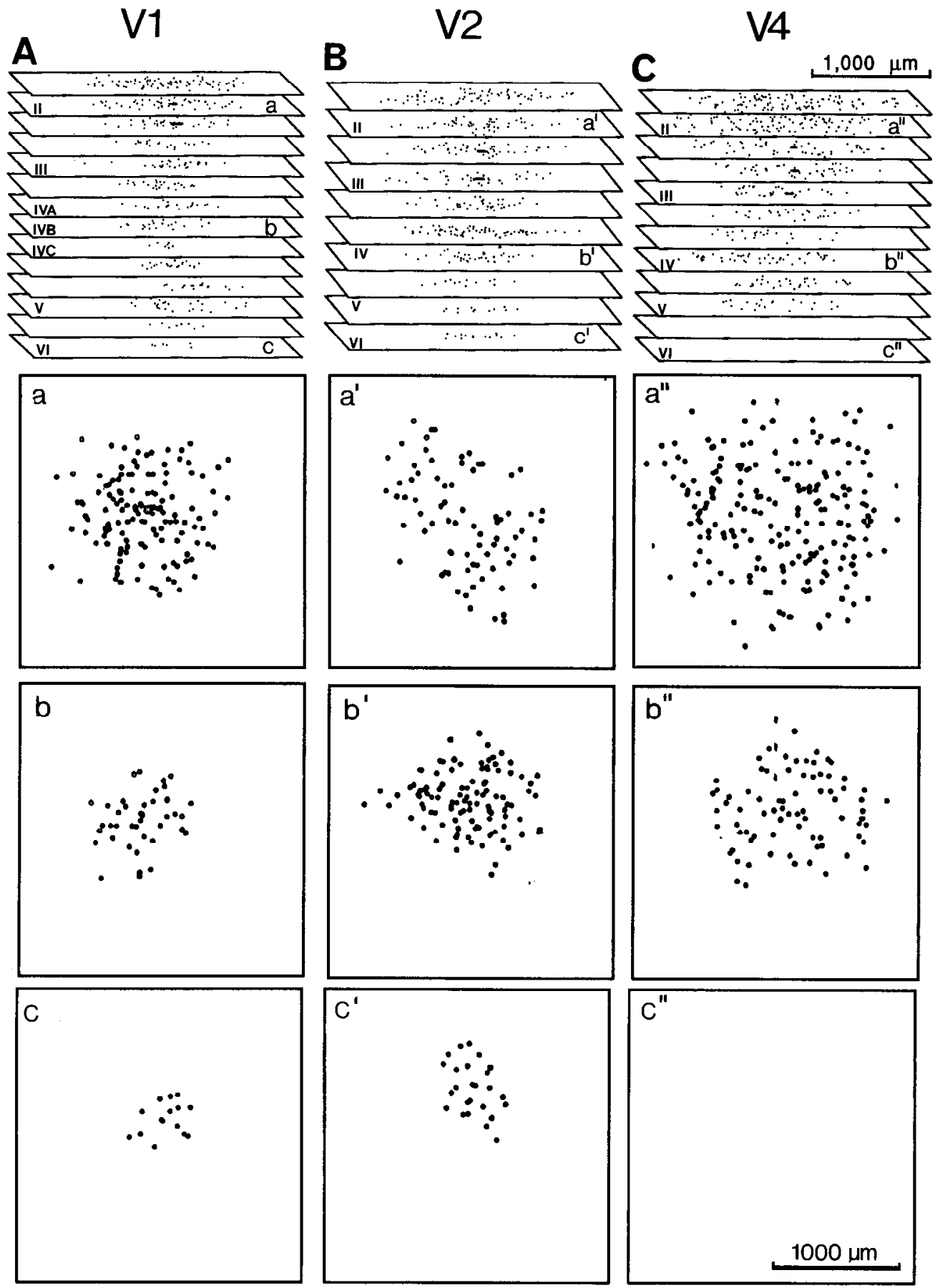

Figure 10. Three-dimensional distributions of neurons (small dots) retrogradely labeled following injection of ${ }^{3} \mathrm{H}$-nipecotic acid $(10 \mathrm{nl}, 0.38 \mathrm{~mm})$ into layers II/III (shaded areas; see arrows) of area V1 $(A), \mathrm{V} 2(B)$, and V4 $(C)$. Comparable injections in all three visual areas produce widespread labeling superficially, and more restricted labeling in deeper cortical layers, but layerby-layer differences in the lateral extent of retrograde labeling are greatest for area V1. Horizontal sections reconstructed from layers II/III $\left(a, a^{\prime}, a^{\prime \prime}\right)$, IV $\left(b, b^{\prime}, b^{\prime \prime}\right)$, and VI $\left(c, c^{\prime}, c^{\prime \prime}\right)$ show that retrograde labeling in superficial cortical layers is elongated along the anteroposterior axis in V2 $\left(a^{\prime}\right)$, but is circularly symmetric for V1 $(a)$ and V4 $\left(a^{\prime \prime}\right)$; a greater lateral spread of label in V4 $\left(a^{\prime \prime}\right)$ distinguishes label in this area from that of VI $(a)$. Labeling in layer IV is distributed circularly in all three visual areas $\left(b, b^{\prime}, b^{\prime \prime}\right)$, but is most dense in V2 $\left(b^{\prime}\right)$ and most laterally extensive in V4 $\left(b^{\prime \prime}\right)$. Layer VI labeling is sparse in areas $\mathrm{V} 1(c)$ and V2 $\left(c^{\prime}\right)$, but is absent in area V4 $\left(c^{\prime \prime}\right)$. up to 1-2.0 mm (e.g., Marin-Padilla, 1969; Martin et al., 1983; Somogyi et al., 1983b; Kisvarday et al., 1987; Lund, 1987; Lund et al., 1988; Lund and Yoshioka, 1991).

The very long lateral intracortical connections, especially prominent in deep cortical layers, thus arise exclusively from pyramidal cells. Current source-density analyses further indicate that most long-range horizontal connections involve pyramidalto-pyramidal cell contacts (Luhmann et al., 1990b), a finding consistent with earlier degeneration studies that revealed that the predominant targets of the terminals of the degenerating pyramidal cells were dendritic spines (Fisken et al., 1975). However, a small percentage of pyramidal cell terminals do contact smooth cells (e.g., Kisvarday et al., 1986b; Gabbott et al., 1987;
LeVay, 1988; McGuire et al., 1991); therefore, local inhibitory mechanisms may be engaged in association with a proportion of these laterally extensive excitatory connections. Nonetheless, the range of laterally directed inhibitory connections themselves (in all but layer IV, IVC for area V1) established in this study and in previous ones using ${ }^{3} \mathrm{H}-\mathrm{GABA}$, intracellular, or Golgi impregnation methodology is clearly sufficient to provide both intra- and intercolumnar influence. The range of inhibitory connections relative to, for example, the 700-800 $\mu \mathrm{m}$ widths of hypercolumns (Hubel and Wiesel, 1974) suggests that inhibitory neurons can link columns of both like and disparate tuning.

In addition to basic similarities in the horizontal patterning of inhibitory connections in V1, V2, and V4, differences were 
always noted between patterns of label produced by comparably placed injections across the striate and extrastriate visual areas (see Fig. 10). For example, the shift between layers in which labeling was widespread and those in which labelling was more laterally restricted was clearest in area V1. The lateral extent of labeling in layers II and III in conjunction with superficial cortical injections, for example, was more than four times the radius of labeling in deep cortical layers. Comparable injections in V2 and V4, however, produced labeling in superficial layers that was often only less than twice the radius of label in infragranular layers. This basic difference in organization, which is also demonstrable for injections in infragranular cortical layers, parallels the strategies adopted by striate and extrastriate cortices for maintaining separation of visual information. Thus, GABAergic connections vary markedly from layer to layer in V1, where different streams of visual information are superimposed upon one another in distinct cortical layers (e.g., Livingstone and Hubel, 1988; Zeki and Shipp, 1988). In V2 and V4, on the other hand, where channels of visual information are distributed side by side, spanning the depths of the cortex (e.g., DeYoe and Van Essen, 1985; Zeki and Shipp, 1989), differences in intralaminar inhibitory projections are much less prominent.

Distinctions are also present in the topography and lateral extent of horizontal cell labeling (see Fig. 10). Injections in V1 and $\mathrm{V} 4$, for example, produce labeling that, within any given layer, is distributed in a roughly circular pattern, while in V2, injections produce elliptical patterns of labeling that mimic the contours of the $\mathrm{CO}$ stripes, that is, are elongated along the anterior-posterior axis. Comparably placed injections produce cell labeling in V2 whose long axis is typically larger than the radius of labeling for the same layer in $\mathrm{V} 1$; the radius of label in the corresponding layer in V4, however, is always greatest. Thus, a systematic increase in the lateral spread of inhibitory connections is seen from striate to extrastriate areas. A similar stepwise lengthening has previously been noted for intracortical pyramidal cell connections revealed by extracellular injections of HRP where patches of label were found as far as 2, 3, and 4 $\mathrm{mm}$ from injection sites in $\mathrm{Vl}, \mathrm{V} 2$, and $\mathrm{V} 4$, respectively (see Rockland, 1983, 1985; Rockland and Lund, 1983). However, increases in the lateral extent of intracortical connections are small relative to the observed enlargement of, for example, receptive fields from V1 to V4 (see Van Essen and Zeki, 1978; Gattass et al., 1981), which is undoubtedly influenced by divergence of afferent input identified in retrograde tracing studies (e.g., Gilbert and Wiesel, 1981) from area to area.

\section{Relationship to excitatory connections}

In V1, injections of ${ }^{3} \mathrm{H}$-nipecotic acid, particularly in granular and infragranular layers, produce patterns of intralaminar inhibitory connections that are reminiscent of connections revealed by either tracing with HRP (Blasdel et al., 1985), degeneration methods following focal lesions (Creutzfeldt et al., 1977), or retrograde transport of ${ }^{3} \mathrm{H}$-D-aspartate (Kisvarday et al., 1989), which reveals excitatory connections. Injections of ${ }^{3} \mathrm{H}-\mathrm{D}-\mathrm{aspar}-$ tate, HRP, and ${ }^{3} \mathrm{H}$-nipecotic acid in infragranular layers, for example (see Blasdel et al., 1985; Kisvarday et al., 1989), each reveal widespread lateral labeling of neurons in infragranular layers and more laterally restricted labeling in granular and supragranular layers, while injections and lesions in granular layers uniformly result in relatively narrow (approximately $400 \mu \mathrm{m}$ in diameter) columns of labeling or degeneration (but limited to deep cortical layers with ${ }^{3} \mathrm{H}$-aspartate and HRP; see below).
Further, some of the very strong and conserved interlaminar inhibitory connections observed between superficial and deep cortical layers of visual areas are paralleled by intracortical axon collaterals of excitatory pyramidal cells. For example, in V1 strong projections of layer $\mathrm{V}$ pyramids to layer III have been demonstrated by retrograde transport of ${ }^{3} \mathrm{H}-\mathrm{D}$-aspartate (Kisvarday et al., 1989).

Nonetheless, the intrinsic inhibitory and excitatory circuitry of the macaque primary visual cortex show both quantitative and qualitative differences in organization. For example, whereas the widest intralaminar labeling observed in layers II/III for inhibitory connections was only about $1 \mathrm{~mm}$, excitatory connections in these layers revealed by both retrograde tracing and degeneration methods often extend over $2 \mathrm{~mm}$ (Creutzfeldt et al., 1977; Blasdel et al., 1985; Kisvarday et al., 1989). Degeneration and HRP studies also reveal extremely widespread lateral connections in layers IVB and V, extending in many cases up to $5 \mathrm{~mm}$ (Creutzfeldt et al., 1975; Blasdel et al., 1985), which is well beyond the range of any inhibitory connections demonstrated to date. Furthermore, the intralaminar excitatory connections revealed in retrograde labeling in cat visual cortex commonly show a degree of clustering, or a patchy tangential organization (e.g., Katz et al., 1984; Matsubara et al., 1987; Luhmann ct al., 1990a), whcrcas inhibitory connections shown in this study and in a previous examination of cat cortex (Albus et al., 1991) were not only more laterally restricted, but were more uniformly distributed in the horizontal plane.

The basic patterns of inhibitory and excitatory connections to particular cortical layers in some cases also differ markedly. For example, following injections of either HRP or ${ }^{3} \mathrm{H}-\mathrm{D}-\mathrm{as}-$ partate in supragranular layers, a conspicuous band of labeled pyramidal cells, up to $2 \mathrm{~mm}$ wide, stands out in layer V (Kisvarday et al., 1989), whereas injections of ${ }^{3} \mathrm{H}$-nipecotic acid or ${ }^{3} \mathrm{H}-\mathrm{GABA}$ (Somogyi et al., 1981a, 1983a) produce only a narrow column of cell labeling $(0.2-0.3 \mathrm{~mm})$ in infragranular layers. In addition, intracortical excitatory inputs to layer IV (particularly IVC of V1) are almost exclusively derived from layers $\mathrm{V}$ and VI (Lund et al., 1981; Fitzpatrick et al., 1985; Kisvarday et al., 1989), but inhibitory inputs from all cortical layers converge here. This last example has interesting functional implications, particularly in area V1, where the connections of the spiny stellate and pyramidal neurons preserve the separation of parvoand magnocellular streams of visual information across cortical layers (e.g., Lund et al., 1975). Inhibitory connections, which link all of the cortical layers, could provide a means for their interaction (see also Yoshioka and Lund, 1990; Lund and Yoshioka, 1991). In area V2, the possibility also exists for inhibitory connections from deep to superficial cortical layers to participate in the process of integration of feedback or reentry projections from functionally specialized extrastriate cortices such as V4 and V5, since these are more laterally dispersed in layers V and VI than the cells of origin of their reciprocal feedforward connections (Shipp and Zeki, 1989a,b; Zeki and Shipp, 1989). Vertically oriented connections may, in turn, provide a means of conveying this information to overlying layers.

\section{$G A B A$ ergic projections of $V 1$ and $V 2$ : relationship to $C O$}

Staining procedures reflecting the activity of the mitochondrial enzyme $\mathrm{CO}$ have revealed major organizational features of visual areas V1 and V2 in the primate (Wong-Riley, 1979; Horton and Hubel, 1981; Humphrey and Hendrickson, 1983; Tootell et al., 1983). In area V1, striking regions of high $\mathrm{CO}$ activity, 
variably termed blobs, dots, patches, spots, or puffs, are rich in wavelength-tuned neurons, while surrounded interblob zones where levels of $\mathrm{CO}$ activity are much lower contain cells that are orientation selective but broadly tuned to chromaticity (Livingstone and Hubel, 1984; for review, see Hendrickson, 1985). Parallels in functional and histochemical organization are also present in area $\mathrm{V} 2$, where information relevant to the perception of color, form, and motion is arranged side by side in longitudinally extensive strips running perpendicular to the V1/V2 border, identified as thin, pale, and thick CO stripes, respectively (Livingstone and Hubel, 1983; Tootell et al., 1983; DeYoe and Van Essen, 1985; Hubel and Livingstone, 1985, 1987).

In V1, blobs have been shown to contain a relative concentration of glutamic acid decarboxylase-positive terminals (Hendrickson et al., 1981), while GABAergic cell bodies appear more evenly distributed among blob and interblob zones (Hendry et al., 1987; Fitzpatrick et al., 1987). Anatomical tracing studies have shown that neurons situated within blobs project selectively to other blobs, and interblob zones have been shown to be similarly and selectively interconnected (Livingstone and Hubel, 1984; but see Rockland and Lund, 1983). Tracing studies in V2 also emphasize orderly and highly selective efferent and afferent (e.g., Livingstone and Hubel, 1983, 1987; DeYoe and Van Essen, 1985; Shipp and Zeki, 1985, 1989b) and, more recently, intrinsic (Ts'o et al., 1990; but see Rockland, 1985) connections between like $\mathrm{CO}$ compartments. Nonetheless, recent physiological studies in V1 have revealed small numbers of cells that are selective for both orientation and wavelength within or adjacent to blobs (Ts'o and Gilbert, 1988) and similar oriented and chromatically tuned neurons lying near the borders between thin and pale stripes in V2 have also been recorded (Ts'o et al., 1990). Thus, physiological studies suggest an interaction among visual channels of information, the substrates of which have not been demonstrated in tracing studies using HRP or Golgi impregnation. In the present study, however, we found evidence suggesting that GABAergic connections may in part serve in this capacity, since some GABAergic connections cross $\mathrm{CO}$ boundaries. These links between $\mathrm{CO}$ compartments account for only a small percentage of the labeling produced by injections placed cleanly in $\mathrm{CO}$ compartments, and these small populations of inhibitory neurons may have been overlooked in studies employing HRP, which tend to emphasize the connections of pyramidal cells. Nonetheless, these inhibitory connections must be further explored by other methods to eliminate vagaries regarding the effective tracer uptake zone. However, in view of vertical GABAergic connections linking functionally dissimilar cortical layers in V1 (present study) and physiological evidence of inhibitory connections linking regions with, for example, dissimilar orientation preference (e.g., Tsumoto et al., 1979; Toyama et al., 1981; Morrone et al., 1982; Matsubara et al., 1987; Hata et al., 1988), horizontal inhibitory connections may mediate interactions between the functionally specialized $\mathrm{CO}$ marked subdivisions.

\section{Relevance of connections to functional properties}

Altempts to understand the construction of the receptive field properties of orientation and direction selectivity have focused in recent years on intracortical circuitry, often with particular attention paid to roles for inhibitory elements. In the case of orientation, mechanisms of isoorientation inhibition, that is, inhibition from cells with similar tuning (e.g., Heggelund, 1981), or cross-orientation inhibition, where inhibition takes place be- tween cells of opposite tuning (e.g., Bishop et al., 1973; Creutzfeldt et al., 1974), are frequently invoked (see also Ferster and Koch, 1987; Martin, 1988b). Several of these theories require a periodicity among inhibitory connections parallel with columnar and/or retinotopic constraints. In the primary visual cortex of macaques, neurons that display orientation selectivity are present in all layers, excluding the thalamorecipient layer IVC (e.g., Blasdel and Fitzpatrick, 1984). In the present study, although retrograde labeling showed some unevenness in density, we saw no evidence of anisotropies in retrograde labeling in layers II/III or V/VI following any injections that could be reconciled with, for example, the dimensions of hypercolumns mapped physiologically in rhesus monkeys. Rather, retrogradely labeled GABAergic neurons showed a more or less even tangential distribution about injection sites, suggesting that neurons lying within the zone of effective tracer uptake receive inhibitory influence from neurons tuned to a range of orientations. Thus, our findings are not readily reconciled with models requiring highly selective interactions among neurons of specific tuning, but instead favor the more recent suggestions that less strictly specified and, as a population, more broadly tuned inputs may provide the basis for orientation selectivities of cortical neurons (e.g., Albus and Baumfalk, 1989; Bonds, 1989; Worgotter and Koch, 1991). Further, the patterns of GABAergic neurons seen in the present study following injections in layers containing oriented cells correspond closely to the distribution of inhibitory neurons identified in recent computer simulations of cat visual cortex that most effectively mimic the computation properties of real cortical neurons (Worgotter and Koch, 1991), that is, combinations of local (within $200 \mu \mathrm{m}$ ) and circular (annular arrays some $500 \mu \mathrm{m}$ in diameter) inhibition. In addition, simulations involving schemes of only local inhibition were claimed to be incompatible with orientation selectivity of cortical neurons (Worgotter and Koch, 1991). It is of interest, therefore, that neurons labeled by injections of ${ }^{3} \mathrm{H}$-nipecotic acid in layer IVC, a layer in which oriented neurons are conspicuously absent (e.g., Blasdel and Fitzpatrick, 1984), are all grouped within about $0.25 \mathrm{~mm}$ of the injection site. Finally, that the patterns of ${ }^{3} \mathrm{H}$ nipecotic acid labeling produced by injections in layers II/III and V/VI are virtual mirror images of one another suggests that the machinery involved in the construction of receptive field properties is repeated across cortical layers and cortical areas, and is consistent with the findings of Malpeli (1983), which demonstrate a degree of independence among cortical layers in the generation of receptive field properties.

Theories also exist to explain the generation of directional selectivity, where directional bias has long been assumed to require long and presumably anisotropic lateral connections (see Gilbert, 1983). In the present study, we found evidence for sets of laterally directed connections (up to $1 \mathrm{~mm}$ ), remarkable for their strength, exclusively in layer IVB of area V1, a layer noted for its direction-sensitive neurons (e.g., Blasdel and Fitzpatrick, 1984). It is tempting to speculate that these connections, which are observed only in this layer following its specific injection, have particular relevance for the emergence of directional bias in its neurons. Support for this idea comes, again, from recent computer simulations, where a case was made for the participation of circular inhibition in the generation of directional bias (Worgotter and Koch, 1991). However, in these studies, circular inhibition was found to produce a directional bias of only about $20 \%$, while the bias of cortical neurons in vivo is most often reported to be closer to $60 \%$ (see Orban, 1984). Our findings in 
layer IVB suggest that the "circular inhibition" in this layer may be only partial since the very strong lateral inhibitory projections peculiar to this layer seem to show some preference for direction.

Finally, local short-range GABAergic connections have been found in every area of cortex examined irrespective of its function, and this study of primate visual cortices is no exception. Some of the short-range connections identified in this study are probably necessary not for attributes specifically connected with visual response properties, but rather for roles such as those suggested in electrophysiological and anatomical studies, which seem to contribute to cortical function regardless of the nature of activating inputs. Physiological studies in cortical areas, for example, have shown that in every experiment in which a cortical input pathway produced an EPSP, it is invariably followed by an IPSP (e.g., McCormick, 1989), which from intracellular recordings is known to be GABA mediated (e.g., Berman et al., 1991). Rigorous anatomical studies confirm that in addition to contacting spiny, excitatory cells, thalamocortical (e.g., Freund et al., 1985, 1989), corticocortical (Lowenstein and Somogyi, 1990), and local collaterals of cortical pyramidal cells (e.g., Kisvarday et al., 1986b; McGuire et al., 1991) also make synaptic contact with GABAergic neurons. Thus, activation of cortical networks simultaneously involves excitation and inhibition, the latter corresponding to disynaptic inhibition. As has been suggested previously, such generalized recruitment of inhibitory neurons may serve in the regulation of the gain of excitatory inputs (for review, see Somogyi, 1989). Undoubtedly, a portion of the GABAergic connections identified in the present study correspond to substrates of such generalized features of cortical connectivity, and participate in inhibitory functions for the normal operation of cortical networks.

\section{References}

Albus K, Baumfalk U (1989) Bicuculline induced changes in excitability and orientation selectivity of striate cortical neurons. Soc Neurosci Abstr 15:324.

Albus K, Wahle P, Lubke J, Matute C. (1991) The contribution of GABAergic neurons to horizontal intrinsic connections in upper layers of the cat's striate cortex. Exp Brain Res 85:235-239.

Berman NJ, Douglas RJ, Martin KAC, Whitteridge D (1991) Mechanisms of inhibition in cat visual cortex. J Physiol (Lond) 440:697722.

Bishop PO, Coombs JS, Henry GH (1973) Receptive fields of simple cells in the cat striate cortex. J Physiol (Lond) 231:31-60.

Blasdel GG, Fitzpatrick D (1984) Physiological organization of layer 4 in macaque striate cortex. J Neurosci 4:880-895.

Blasdel GG, Lund JS, Fitzpatrick D (1985) Intrinsic connections of macaque striate cortex: axonal projections of cells outside lamina $4 \mathrm{c}$. J Neurosci 5:3350-3369.

Bonds AB (1989) Role of inhibition in the specification of orientation selectivity of cells in the cat striate cortex. Vis Neurosci 2:41-55.

Chronwall BM, Wolff JR (1980) Prenatal and postnatal development of GABA-accumulating cells in the occipital neocortex of the rat. J Comp Neurol 190:187-208.

Creutzfeldt OD, Kuhnt U, Benevento LA (1974) An intracellular analysis of visual cortical neurones to moving stimuli: response in a cooperative neuronal network. Exp Brain Res 21:251-274.

Creutzfeldt OD, Garey LJ, Kuroda R, Wolff J-R (1977) The distribution of degenerating axons after small lesions in the intact and isolated visual cortex of the cat. Exp Brain Res 27:419-440.

Cuenod M, Bagnoli P, Beaudet A, Rustioni A, Wiklund L, Streit P (1982) Transmitter-specific retrograde labeling of neuron. In: $\mathrm{Cy}$ tochemical methods in neuroanatomy (Chan-Palay V, Palay SL, eds), pp 17-44. New York: Liss.

DeFelipe J, Jones EG (1985) Vertical organization of $\gamma$-aminobutyric acid-accumulating intrinsic neuronal systems in monkey cerebral cortex. J Neurosci 5:3246-3260.
DeFelipe J, Hendry SHC, Hashikawa T, Molinari M, Jones EG (1990) A microcolumnar structure of monkey cerebral cortex revealed by immunocytochemical studies of double bouquet cell axons. Neuroscience 37:655-673.

DeYoe EA, Van Essen DC (1985) Segregation of efferent connections and receptive field properties in visual area $V 2$ of the macaque. Nature 317:58-61.

DeYoe EA, Van Essen DC (1988) Concurrent processing streams in monkey visual cortex. Trends Neurosci 11:219-226.

Felleman DJ, Van Essen DC (1991) Distributed hierarchical processing in primate cerebral cortex. Cereb Cortex 1:1-47.

Ferster D, Koch C (1987) Neuronal connections underlying orientation selectivity in cat visual cortex. Trends Neurosci 10:487-492.

Fisken RA, Garey LJ, Powell TPS (1975) The intrinsic association and commissural connections of area 17 of the visual cortex. Philos Trans R Soc Lond [Biol] 272:487-536.

Fitzpatrick D, Lund JS, Blasdel GG (1985) Intrinsic connections of macaque striate cortex: afferent and efferent connections of lamina 4C. J Neurosci 5:3329-3349.

Fitzpatrick D, Lund JS, Schmechel DE, Towles AC (1987) Distribution of GABAergic neurons and axon terminals in the macaque striate cortex. J Comp Neurol 264:73-91.

Freund TF, Martin KAC, Somogyi P, Whitteridge D (1985) Innervation of cat visual areas 17 and 18 by physiologically identified $X$ and $Y$-type thalamic afferents. II. Identification of postsynaptic targets by GABA immunocytochemistry and Golgi impregnation. J Comp Neurol 242:275-291.

Freund TF, Martin KAC, Soltesz I, Somogyi P, Whitteridge D (1989) Arborisation pattern and postsynaptic targets of physiologically identified thalamocortical afferents in striate cortex of the macaque monkey. J Comp Neurol 289:315-336.

Gabbot PLA, Martin KAC, Whitteridge D (1987) Connections between pryamidal neurons in layer 5 of cat visual cortex (area 17). J Comp Neurol 259:364-381.

Gattass R, Gross CG, Sandell JH (1981) Visual topography of V2 in the macaque. J Comp Neurol 201:519-539.

Gilbert CD (1983) Microcircuitry of the visual cortex. Annu Rev Neurosci $6: 217-247$

Gilbert CD, Wiesel TN (1979) Morphology and intracortical projections of functionally characterised neurones in the cat visual cortex. Nature 280:120-125.

Gilbert CD, Wiesel TN (1981) Laminar specialization and intracortical connections in cat primary visual cortex. In: The organization of the cerebral cortex (Schmidt FO, Worden FG, Adelman G, Denis SG, eds), pp 163-194. Cambridge, MA: MIT Press.

Gilbert CD, Wiesel TN (1983) Clustered intrinsic connections in cat visual cortex. J Neurosci 3:1116-1133.

Goldman PS, Nauta WJH (1977) Columnar distribution of corticocortical fibers in the frontal association, limbic and motor cortcx of the developing rhesus monkey. Brain Res 122:393-413.

Hamos JE, Davis TL, Sterling P (1983) Four types of neuron in layer IVab of cat cortical area 17 accumulate ${ }^{3} \mathrm{H}-\mathrm{GABA}$. J Comp Neurol 217:449-457.

Hata Y, Tsumoto T, Sato H, Hagihara K, Tamura H (1988) Inhibition contributes to orientation selectivity in visual cortex of cat. Nature 335:815-817.

Heggelund P (1981) Receptive field organization of simple cells in cat striate cortex. Exp Brain Res 42:89-98.

Hendrickson AE (1985) Dots, stripes and columns in monkey visual cortex. Trends Neurosci 8:406-410.

Hendrickson AE, Hunt SP, Wu J-Y (1981) Immunocytochemical localization of glutamic acid decarboxylase in monkey striate cortex. Nature 292:605-607.

Hendry SHC, Schwark HD, Jones EG, Yan J (1987) Numbers and proportions of GABA-immunoreactive neurons in different areas of monkey cerebral cortex. J Neurosci 7:1503-1519.

Horton JC, Hubel DH (1981) Regular patchy distribution of cytochrome oxidase staining in primary visual cortex of macaque monkey. Nature 292:762-764.

Hubel DH, Livingstone MS (1985) Complex-unoriented cells in a subregion of primate area 18. Nature 315:325-327.

Hubel DH, Livingstone MS (1987) Segregation of form, color, and stereopsis in primate area 18. J Neurosci 7:3378-3415.

Hubel DH, Wiesel TN (1962) Receptive fields, binocular interaction and functional architecture in the cat's visual cortex. J Physiol (Lond) 160:106-154. 
Hubel DH, Wiesel TN (1972) Laminar and columnar distribution of geniculo-cortical fibers in the macaque monkey. J Comp Neurol 146: $421-450$.

Hubel DH, Wiesel TN (1974) Sequence regularity and geometry of orientation columns in the monkey striate cortex. J Comp Neurol 158:267-294.

Humphrey AL, Hendrickson AE (1983) Background and stimulusinduced patterns of high metabolic activity in the visual cortex (area 17) of the squirrel and macaque monkey. J Neurosci 3:345-358.

Johnston GAR, Krogsgaard-Larsen P, Stephanson AL, Twitchin B (1976) Inhibition of the uptake of GABA and related amino acids in rat brain slices by the optical isomers of nipecotic acid. J Neurochem 26:1029-1032.

Katz LC, Burkhalter A, Dreyer WJ (1984) Fluorescent latex microspheres as a retrograde neuronal marker for in vivo and in vitro studies of visual cortex. Nature 310:498-500.

Kisvarday ZF, Cowey A, Hodgson AJ, Somogyi P (1986a) The relationship between GABA immunoreactivity and labelling by local uptake of $\left[{ }^{3} \mathrm{H}\right]-\mathrm{GABA}$ in the striate cortex of monkey. Exp Brain Res 62:89-98.

Kisvarday ZF, Martin KAC, Freund TF, Magloczky Zs, Whitteridge D, Somogyi P (1986b) Synaptic targets of HRP-filled layer III pyramidal cells in the cat striate cortex. Exp Brain Res 64:541-552.

Kisvarday ZF, Cowey A, Somogyi P (1986c) Synaptic relationships of a type of GABA-immunoreactive neuron (clutch cell), spiny stellate cells and lateral geniculate nucleus afferents in layer IVC of the monkey striate cortex. Neuroscience 19:741-761.

Kisvarday ZF, Martin KAC, Friedlander MJ, Somogyi P (1987) Evidence for interlaminar inhibitory circuits in the striate cortex of the cat. J Comp Neurol 260:1-19.

Kisvarday ZF, Cowey A, Smith AD, Somogyi P (1989) Interlaminar and latcral cxcitatory amino acid connections in the striate cortex of monkey. J Neurosci 9:667-682.

Kovalev GI, Raevskii KS (1981) Nipecotic acid, a competitive inhibitor of the net uptake of ${ }^{3} \mathrm{H}-\mathrm{GABA}$ by rat brain synaptosomes. Bull Exp Biol Med 91:692-694.

Krogsgaard-Larsen P, Johnston GAR (1975) Inhibition of GABA uptake in rat brain slices by nipecotic acid, various isoxazoles and related compounds. J Neurochem 25:797-802.

Larsson OM, Krogsgaard-Larsen P, Schousboe A (1980) High-affinity uptake of $(R S)$-nipecotic acid in astrocytes cultured from mouse brain. Comparison with GABA transport. J Neurochem 34:970-977.

LeVay S (1988) Patchy intrinsic projections in visual cortex, area 18, of the cat: morphological and immunocytochemical evidence for an excitatory function. J Comp Neurol 269:265-274.

Livingstone MS, Hubcl DH (1983) Specificity of cortico-cortical connections in monkey visual system. Nature 304:531-534.

Livingstone MS, Hubel DH (1984) Specificity of intrinsic connections in primate primary visual cortex. J Neurosci 4:2830-2835.

Livingstone MS, Hubel DH (1987) Connections between layer 4B of area 17 and the thick cytochrome oxidase stripes of area 18 in the squirrel monkey. J Neurosci 7:3371-3377.

Livingstone M, Hubel D (1988) Segregation of form, color, movement, and depth: anatomy, physiology, and perception. Science 240:740749.

Lorente de No R (1922) La corteza cerebral del raton. I. La corteza acustica. Trab Lab Invest Biol (Univ Madrid) 20:41-78.

Lorente de No R (1938) The cerebral cortex: architecture, intracortical connections and motor projections. In: Physiology of the nervous system, 2d ed (Fulton JF, cd), pp 291-321. Ncw York: Oxford UP.

Lowenstein PR, Somogyi P (1990) Synaptic organization of corticocortical connections from the primary visual cortex to the posteromedial lateral suprasylvian visual area in the cat. J Comp Neurol 310:253-266.

Luhmann HJ, Singer W, Martinez-millan L (1990a) Horizontal interactions in cat striate cortex. I. Anatomical substrate and postnatal development. Eur J Neurosci 2:344-357.

Luhmann HJ, Greuel JM, Singer W (1990b) Horizontal interactions in cat striate cortex. II. A current source-density analysis. Eur J Neurosci 2:358-368.

Lund JS (1987) Local circuit neurons of macaque monkey striate cortex. I. Neurons of laminae 4C and 5A. J Comp Neurol 257:6092.

Lund JS, Boothe RG (1975) Interlaminar connections and pyramidal neuron organization in the visual cortex, area 17, of the macaque monkey. J Comp Neurol 159:305-334.
Lund JS, Yoshioka T (1991) Local circuit neurons of macaque monkey striate cortex. III. Neurons of laminae 4B, 4A, and 3B. J Comp Neurol 311:234-258

Lund JS, Lund RD, Hendrickson AE, Bunt AH, Fuchs AF (1975) The origin of efferent pathways from the primary visual cortex, area 17, of the macaque monkey as shown by retrograde transport of horseradish peroxidase. J Comp Neurol 164:287-304.

Lund JS, Hendrickson AE, Ogren MP, Tobin EA (1981) Anatomical organization of primate visual cortex area VII. J Comp Neurol 202: $19-45$.

Lund JS, Hawken MJ, Parker AJ (1988) Local circuit neurons of macaque monkey striate cortex. II. Neurons of laminae $5 \mathrm{~B}$ and 6 . J Comp Neurol 276:1-29.

Malpeli JG (1983) Activity of cells in area 17 of the cat in absence of input from layer $A$ of lateral geniculate nucleus. J Neurophysiol 49: 595-610.

Marin-Padilla M (1969) Origin of the pericellular baskets of the pyramidal cells of the human motor cortex: a Golgi study. Brain Res 14:633-646.

Martin KAC (1988a) From enzymes to visual perception: a bridge too far? Trends Neurosci 11:380-387.

Martin KAC (1988b) The Wellcome Prize lecture. From single cells to simple circuits in the cerebral cortex. Q J Exp Physiol 73:637-702.

Martin KAC, Whitteridge D (1984) Form, function and intracortical projections of spiny neurons in the striate visual cortex of the cat. $J$ Physiol (Lond) 353:463-504.

Martin KAC, Somogyi P, Whitteridge D (1983) Physiological and morphological properties of identified basket cells in the cat's visual cortex. Exp Brain Res 50:193-200.

Martinotti C (1889) Contributo allo studio della corteccia cerebrate, ed all origine centrale dei nervi. Ann Freniatr Sci Affini 1:314-381.

Matsubara JA, Cynader MS, Swindale NV (1987) Anatomical properties and physiological correlates of the intrinsic connections in cat area 18. J Neurosci 7:1428-1446.

McCormick DA (1989) GABA as an inhibitory neurotransmitter in human cerebral cortex. J Neurophysiol 62:1018-1027.

McGuire BA, Gilbert CD, Rivlin PK, Wiesel TN (1991) Targets of horizontal connections in macaque primary visual cortex. J Comp Neurol 305:370-392.

Moran J, Desimone R (1985) Selective attention gates visual processing in extrastriate cortex. Science 229:782-784.

Morrone MC, Burr DC, Maffei L (1982) Functional implications of cross-orientation inhibition of cortical visual cells. I. Neurophysiological evidence. Proc R Soc Lond [Biol] 216:335-354.

Mountcastle VB (1957) Modality and topographic properties of single neurons of cat's somatic sensory cortex. J Neurophysiol 20:408-434.

Nauta HJW, Butler AB, Jane JA (1973) Some observations on axonal degeneration resulting from superficial lesions of the cerebral cortex. J Comp Neurol 150:349-360.

Orban GA (1984) Studies of brain function, Vol 11, Neuronal operations in the visual cortex. Berlin: Springer.

Peters A, Kegidor J (1981) A reassessment of the forms of nonpyramidal neurons in area 17 of cat visual cortex. J Comp Neurol 203:685716.

Ramon y Cajal S (1891) Sur la structure de l'ecorce cerebrale de quelques mammiferes. Cellule 7:3-54.

Ramon y Cajal S (1911) Histologie du systeme nerveux de l'homme et des vertebres, Vol 2, No 244 (Azoulay S, transl). Paris: Maloine.

Rockland KS (1983) Lattice-like intrinsic neural connections in macaque prestriate visual cortex. Soc Ncurosci Abstr 9:476.

Rockland KS (1985) A reticular pattern of intrinsic connections in primate area V2 (area 18). J Comp Neurol 235:467-478.

Rockland KS, Lund JS (1983) Intrinsic laminar lattice connections in primate visual cortex. J Comp Neurol 216:303-318.

Schein SJ, Desimone R (1990) Spectral properties of V4 neurons in the macaque. J Neurosci 10:3369-3389.

Schwartz ML, Zheng D-S, Goldman-Rakic PS (1988) Periodicity of GABA-containing cells in primate prefrontal cortex. J Neurosci 8: 1962-1970.

Shipp S, Zeki S (1985) Segregation of pathways leading from area V2 to areas V4 and V5 of macaque monkey visual cortex. Nature 315: 322-325.

Shipp S, Zeki S (1989a) The organization of connections between areas V5 and V1 of macaque monkey visual cortex. Eur J Neurosci 1:309332.

Shipp S, Zeki S (1989b) The organization of connections between areas 
V5 and V2 of macaque monkey visual cortex. Eur J Neurosci 1:333354

Silverman MS, Tootell RBH (1987) Modified technique for cytochrome oxidase histochemistry: increased staining intensity and compatibility with 2-deoxyglucose autoradiography. J Neurosci Methods 19:1-10.

Somogyi $P$ (1989) Synaptic organization of GABAergic neurons and $\mathrm{GABA}_{\mathrm{A}}$ receptors in the lateral geniculate nucleus and visual cortex. In: Neural mechanisms of visual perception (Lam DK-T, Gilbert CD, eds), pp 35-62. Houston: Portfolio.

Somogyi P, Cowey A (1981) Combined Golgi and electron microscopic study on the synapses formed by double houquet cells in the visual cortex of the cat and monkey. J Comp Neurol 195:547-566.

Somogyi P, Cowey A, Halasz N, Freund TF (1981a) Vertical organization of neurons accumulating ${ }^{3} \mathrm{H}-\mathrm{GABA}$ in visual cortex of rhesus monkey. Nature 294:761-763.

Somogyi P, Freund TF, Halasz N, Kisvarday ZF (1981b) Selectivity of neuronal $\left[{ }^{3} \mathrm{H}\right] \mathrm{GABA}$ accumulation in the visual cortex as revealed by Golgi staining of the labeled neurons. Brain Res 225:431-436.

Somogyi P, Cowey A, Kisvarday ZF, Freund TF, Szentagothai J (1983a) Retrograde transport of $\gamma$-amino[ $\left.{ }^{3} \mathrm{H}\right]$-butyric acid reveals specific interlaminar connections in the striate cortex of monkey. Proc Natl Acad Sci USA 80:2385-2389.

Somogyi P, Kisvarday ZF, Martin KAC, Whitteridge D (1983b) Synaptic connections of morphologically identified and physiologically characterized large hasket cells in the striate cortex of cat. Neuroscience 10:261-294.

Somogyi P, Hodgson AJ, Chubb IW, Penke B, Erdei A (1985) Antiserum to $\gamma$-aminobutyric acid. II. Immunocytochemical application to the central nervous system. J Histochem Cytochem 33:245-248.

Spatz WB, Tigges J, Tigges M (1970) Subcortical projections, cortical associations, and some intrinsic interlaminar connections of the striate cortex in the squirrel monkey (Saimiri). J Comp Neurol 140:155174.

Streit P, Knecht E, Cuenod M (1979) Transmitter-specific retrograde labeling in the striato-nigral and raphae-nigral pathways. Science 205: 306-308.

Szentagothai J (1965) The use of degeneration methods in the investigation of short neuronal connections. Prog Brain Res 14:1-22.

Szentagothai J (1969) Architecture of the cerebral cortex. In: Basic mechanisms of the epilepsies (Jasper HH, Ward AA, Pope A, eds), pp 13-28. Boston: Little, Brown.

Tootell RBH, Silverman MS, DeValois RL, Jacobs GH (1983) Func- tional organization of the second cortical visual arca in primates. Science 220:737-739.

Toyama K, Kimura M, Tanaka K (1981) Organization of cat visual cortex as investigated by cross-correlation technique. J Neurophysiol 46:206-214.

Ts'o DY, Gilbert CD (1988) The organization of chromatic and spatial interactions in the primate striate cortex. J Neurosci 8:1712-1727.

Ts'o DY, Gilbert CD, Wiesel TN (1990) Functional architecture of color and disparity in visual area 2 of macaque monkey. Soc Neurosci Abstr 16:293.

Tsumoto T, Eckart W, Creutzfeldt OD (1979) Modification of orientation sensitivity of cat visual cortex neurons by removal of GABAmediated inhibition. Exp Brain Res 34:351-363.

Valverde $F$ (1971) Short axon neuronal subsystems in the visual cortex of the monkcy. Int J Ncurosci 1:181-197.

Van Essen DC, Zeki SM (1978) The topographic organization of rhesus monkey prestriate cortex. J Physiol (Lond) 277:193-226.

Wolff JR, Chronwall BM (1982) Axosomatic synapses in the visual cortex of the adult rat. A comparison between GABA-accumulating and other neurons. J Neurocytol 11:409-425.

Wong-Riley $M$ (1979) Changes in the visual system of monocularly sutured or enucleated cats demonstrable with cytochrome oxidase histochemistry. Brain Res 171:11-28.

Worgotter F, Koch C (1991) A detailed model of the primary visual pathway in the cat: comparison of afferent excitatory and intracortical inhibitory connection schemes for orientation selectivity. J Neurosci 11:1959-1979.

Yoshioka T, Lund JS (1990) Substrates for interaction of visual channels within area 17 of monkey visual cortex. Soc Neurosci Abstr 16: 707.

Zeki SM (1978) Uniformity and diversity of structure and function in rhesus monkey prestriate visual cortex. J Physiol (Lond) 277:273290.

Zeki SM (1983) Color coding in the cerebral cortex: the reaction of cells in the monkey visual cortex to wavelengths and colors. Neuroscience 9:741-765.

Zeki S, Shipp S (1988) The functional logic of cortical connections. Nature 335:311-317.

Zeki S, Shipp S (1989) Modular connections between areas V2 and V4 of macaque monkey visual cortex. Eur J Neurosci 1:494-506.

Zucker C, Yazulla S, Wu J-Y (1984) Non-correspondence of $\left.{ }^{3} \mathrm{H}\right]-$ GABA uptake and GAD localization in goldfish amacrine cells. Brain Res 298:154-158. 